\title{
Information, uncertainty, and subjective entitlements in bargaining
}

Citation for published version (APA):

Karagozoglu, E., \& Riedl, A. M. (2010). Information, uncertainty, and subjective entitlements in bargaining. METEOR, Maastricht University School of Business and Economics. METEOR Research Memorandum No. 043 https://doi.org/10.26481/umamet.2010043

Document status and date:

Published: 01/01/2010

DOI:

10.26481/umamet.2010043

Document Version:

Publisher's PDF, also known as Version of record

\section{Please check the document version of this publication:}

- A submitted manuscript is the version of the article upon submission and before peer-review. There can be important differences between the submitted version and the official published version of record.

People interested in the research are advised to contact the author for the final version of the publication, or visit the DOI to the publisher's website.

- The final author version and the galley proof are versions of the publication after peer review.

- The final published version features the final layout of the paper including the volume, issue and page numbers.

Link to publication

\footnotetext{
General rights rights.

- You may freely distribute the URL identifying the publication in the public portal. please follow below link for the End User Agreement:

www.umlib.nl/taverne-license

Take down policy

If you believe that this document breaches copyright please contact us at:

repository@maastrichtuniversity.nl

providing details and we will investigate your claim.
}

Copyright and moral rights for the publications made accessible in the public portal are retained by the authors and/or other copyright owners and it is a condition of accessing publications that users recognise and abide by the legal requirements associated with these

- Users may download and print one copy of any publication from the public portal for the purpose of private study or research.

- You may not further distribute the material or use it for any profit-making activity or commercial gain

If the publication is distributed under the terms of Article $25 \mathrm{fa}$ of the Dutch Copyright Act, indicated by the "Taverne" license above, 


\section{Maastricht University}

Emin Karagözoğlu, Arno Riedl

I nformation, Uncertainty and Subjective Entitlements in Bargaining

$\mathrm{RM} / 10 / 043$

\section{METEOR}

Maastricht University School of Business and Economics

Maastricht Research School of Economics

of Technology and Organization

\section{P.O. Box 616}

NL - 6200 MD Maastricht

The Netherlands 


\title{
Information, Uncertainty, and Subjective Entitlements in Bargaining*
}

\author{
Emin Karagözoğlu ${ }^{\dagger} \quad$ Arno Riedl ${ }^{\ddagger}$
}

This version: July 2010

\begin{abstract}
More often than not production processes are the joint endeavor of people having different abilities and productivities. Such production processes and the associated surplus production are often not fully transparent in the sense that the relative contributions of involved agents are blurred; either by lack of information about the actual performance of collaborators or because of random noise in the production process or both. These variables likely influence the surplus sharing negotiations following the production. By means of a laboratory experiment, we systematically investigate their role for the whole bargaining process from opening offers to (dis)agreements and find that uncertainties in surplus production and (even) a very coarse performance information lead to bargaining asymmetries. In addition, we find that bargainers' subjective entitlements are also influenced by performance information and the randomness inherent in the production process. These differences in subjective entitlements together with the differences in entitlements between better and worse performers influence the whole bargaining process and significantly contribute to the differences in bargaining outcomes.
\end{abstract}

Keywords: bargaining; performance information; randomness in production process; entitlements; experiments.

${ }^{*}$ We would like to thank Gary Bolton, Elena Cettolin, Simon Gächter, Sebastian Kranz, Dan Levin, Ronald Peeters, Philipp Reiss, Ernesto Reuben, Alvin Roth, Daniel Seidmann, Chris Starmer, Martin Strobel, Alexander Vostroknutov, Christian Zehnder, Ping Zhang, and conference and seminar participants in Antwerp, Copenhagen, East Anglia, Harvard, Koç, Maastricht, Nice, Nottingham, PennState, and Rotterdam. Parts of this research were completed while the first author was visiting the Center for Decision Research and Experimental Economics at the Nottingham School of Economics, Sabancı University, and Harvard Business School. We would like to thank the host institutions for their hospitality. Research funding by the Oesterreichische Nationalbank through her Anniversary Fund (project no. 11780) is very much appreciated. All remaining errors are ours.

${ }^{\dagger}$ Maastricht University, Department of Economics, P.O. Box 616, 6200 MD, Maastricht, The Netherlands, Email: E.Karagozoglu@maastrichtuniversity.nl.

${ }^{\ddagger}$ CESifo, IZA, and Maastricht University, Department of Economics, P.O. Box 616, 6200 MD, Maastricht, The Netherlands, Email: a.riedl@maastrichtuniversity.nl. 


\section{Introduction}

In the season of 1998-1999, a players' strike lasting 191 days shook the National Basketball League (NBA). Due to the strike the players lost in total about USD 500 million of income, the owners lost about USD 1 Billion and the NBA lost billions of dollars because of dropped ratings. Ironically, the strike set in at a time when the NBA was experiencing very high ratings and generating large revenues from broadcast and advertisement agreements (Donovan 1998). One important reason for the strike was that the players thought that "the league has had enormous growth, globally even" and "players just want their fair share" (Donovan 1998), whereas the team owners argued that they are already paying too much to the players. ${ }^{1}$ A major disagreement underlying this dispute concerned the question of the relative contributions of players and team owners to the success of the NBA. In a completely different business area, a similar conflict was reported between the voice actor of a popular computer game and the company owning the rights of the game. The involved parties strongly disagreed on their relative contribution to the sales success of the game, and in consequence, on the relative fair share of the gains they felt entitled to (Schiesel 2008). ${ }^{2}$

Disagreements about how to share a jointly produced surplus do not only occur in cases of unexpected success but also, and probably more fiercely, in situations of economic distress. Discussions and disputes about how to share the burden between white collar and blue collar workers or between management and workers during business and economic crises come to mind (Corfman and Shmeltzer 2002; Buhayar 2009; Lyons 2009). A recent example is the economic crisis in Greece: on February 10, 2010, thousands of people hit the streets of Athens to protest the Greek government's belt-tightening program amid a deep economic crisis. Their message was that the crisis is mainly due to the wrong-doings of the high-level managers and corrupt business practices in the financial sector and hence the burden should be put on them, not on the low-income, blue-collar workers. Also in the (semi-)public sphere discussions about how to share the fruits of success and the burden of distress are frequent. In academic institutions financial distress leads to less liquidity and, hence, necessary cuts in departments' budgets. In such situations, while most agree on the necessity of cuts, there is much disagreement about the distribution of the burden and how it is going to be determined (Jan 2009). Another example are arising discussions and conflicts when it comes to

\footnotetext{
${ }^{1}$ The cited statements are taken from the speech of Atlanta Hawks forward and member of the union's executive committee, Tyrone Corbin.

${ }^{2}$ The computer game Grand Theft Auto IV became the fastest selling game to date when it was released on December 2, 2008 in the United States. It sold about 3.7 million copies on its first day, generating at least USD 500 million revenue in the first week (Ortutay 2008; Totilo 2008). The voice actor (Michael Hollick) and the company (Rockstar Games) haggled about the relative contributions of the "human performance" and the "conception of the art director" to the success of the game.
} 
reforms of public pensions or health insurance systems, where the conflict often centers around the question of the relative burden different generations and different income groups have to carry.

How different these examples are, they are all related to the fact that economic surplus is the joint product of different people whose interests diverge when it comes to the division of the jointly created surplus. Agreements on how to divide the surplus may seem easy if it is without doubt determined by the contributions of all involved parties and when there is complete information of the relative contributions. However, often, if not most of the time, the relative contributions of the involved parties cannot be precisely determined and success and failure is at least partly determined by random factors inherent to the production process. The (lack of) information and the (un)certainties in the production process may lead to disagreements among the parties and, hence, may influence the outcomes of negotiations on how to share the produced surplus. In addition, there is evidence that such negotiations can be influenced by entitlements and obligations parties bring to the bargaining table (Thompson and Loewenstein 1992; Babcock et al. 1996; Gächter and Riedl 2005).

Interestingly, there is no clean evidence on how relative performance information and information about the influence of exogenous factors in surplus creation affects bargaining outcomes. Such evidence is important, however, because a good understanding of the influences of these factors on bargaining behavior may help to avoid discussions and potentially costly conflicts as reported above. In addition, in the reported examples the involved parties often explicitly or implicitly refer to their (perceived) entitlements when arguing in their own favor. For instance, in the NBA conflict players claimed that they only wanted their fair share and in political discussions around pension reforms it is often the older generation which argues that they have contributed to the increase in wealth and are, hence, now entitled to their fair share. In view of this, it is surprising that little is known about the interaction between information on relative contributions and uncertainties in surplus creation and entitlements in bargaining.

In this paper we implement a $2 \times 2$ experimental design to investigate the effects of relative performance information and random noise in the production process on bargaining behavior, and to explore how these factors interact with subjective entitlements. ${ }^{3}$ Specifically, in one condition the surplus is produced by the performance of two subjects in a real effort task in a deterministic way, whereas in another condition the surplus size is also influenced by a random factor. To investigate the effect of relative performance information, in one condition we inform subjects in a bargaining

\footnotetext{
${ }^{3}$ In the literature, the term "entitlement" is not always used in the same way. In our study we use the term as defined by Schlicht (1998, p.24): "Entitlements are rights, as perceived by the individual. They are not, however, abstract legal rights. Rather they denote the subjectively perceived rights that go along with a motivational disposition to defend them."
} 
pair whether (s)he has been the better or worse performer, whereas such information is not given in another condition. In addition, in all conditions we elicit subjects' subjective entitlements by way of a fairness question as in Gächter and Riedl (2005). After production subjects have to bargain on the distribution of the surplus in a computerized free-form bargaining environment, where we can trace all important elements of the negotiation process from opening proposals, concession behavior, bargaining duration, and (dis)agreements.

We find that information about the relative performance as well as (the absence of) noise in the surplus production affect bargaining behavior at all levels. Compared to the situation without performance information, in the condition with performance information opening proposals and agreements are skewed away from an equal split in favor of the party that performed better in the real effort task. In addition, relative performance information leads to smaller and later concessions and longer bargaining duration. Furthermore, in comparison to surplus production with noise, opening proposals favor the better performing party, concessions are smaller and later, and bargaining duration is longer, when the surplus creation is deterministic.

Subjective entitlements play an important role in explaining differences in bargaining outcomes within as well as between conditions. First, probably unsurprisingly, entitlements of better and worse performers differ and they differ most in the condition with relative performance information. Second, and more importantly, we can trace the differential influence of entitlements among the different conditions through the whole bargaining process. In all conditions, opening proposals of better performers are significantly positively influenced by their entitlements. This does not hold for worse performers. Concession behavior and bargaining duration are strongly related to the tension in entitlements between better and worse performers, but only in conditions with performance information and deterministic surplus production. In consequence, in these conditions, bargaining durations are also influenced by entitlements. When the production process is deterministic also agreements are strongly influenced by entitlements of the better performing subject, but not by the worse performing subject. In summary, we find that the knowledge of relative performances in the real effort task as well as the randomness of the production process differentially influence bargaining behavior, and that much of this differences are mediated by subjective entitlements bargainers derive in the production process.

The rest of the paper is organized as follows. The next section provides a brief overview of the related literature. Section 3 presents the experimental design and procedures, Section 4 reports the results and Section 5 concludes. 


\section{Related Literature}

There are only a handful of papers, which examine the influence of fairness judgments (or subjective entitlements) on negotiations. Messick and Sentis (1979) report results from an experiment showing that subjects' fairness judgments are self-servingly biased. Thompson and Loewenstein (1992) also find that subjects' fairness interpretations are egocentric and that these biases cause delays in settlement and that the magnitude of these biases predicts the length of delays in agreements. Along the same lines, Babcock and Loewenstein (1997) show that self-servingly biased assessments of fairness can delay agreements and cause impasse even when the fairness assessments are common knowledge or impartial. More recently, Gächter and Riedl (2005) find strong entitlement effects that shape all layers of the negotiation process and they argue that entitlements constitute a "moral property right" that is influential independent of negotiators' legal property rights.

Standard bargaining theory predicts that more information leads to more efficient bargaining by reducing information asymmetries between bargaining parties and, hence, strategic delays (Rubinstein 1985; Admati and Perry 1987). However, Camerer and Loewenstein (1993) show that increasing the information available to bargainers may lead to less efficient bargaining. The main reason for this is that the information provided to bargainers may strengthen the tension between their fairness judgments and this effect may offset the positive effect information is supposed to have. ${ }^{4}$ Babcock, Loewenstein, Issacharoff and, Camerer (1995) and Loewenstein and Moore (2004) are other studies, which also showed that sharing information may lead diverging perceptions of fairness and, hence, make settlements less likely.

To the best of our knowledge, there is no study that examines the influence of noise in the surplus production process on the bargaining of how to share the produced surplus. Diekmann et al. (2004) argue that when people face increased uncertainty, fairness becomes more important to them and fairness judgments affect their reactions more strongly. However, their study investigates the influence of uncertainty about performance standards and appropriate behaviors on the relationship between fairness and job satisfaction. Babcock, Loewenstein and Wang (1995) study the effect of uncertainty about the bargaining opponent's reservation value and show that uncertainty

\footnotetext{
${ }^{4}$ When motivating their argument they present the following interesting example about the potentially negative influence of information on bargaining outcomes: "For example, suppose two people contribute different amounts of time to a joint project. The person who worked less will typically think that equal compensation is fair, while the person who worked more will think that payments should be proportional to effort (Messick and Sentis 1983). If the parties bargain over how to split the proceeds from the project and each know how much the other worked, they may have difficulty in agreeing up on a split, since the one who worked more will demand a larger share of the proceeds while the one who worked less will demand an equal share. If the parties did not know how much the other put in, however, they could not base compensation on input levels and they might be more likely to settle."
} 
decreases bargaining efficiency. A related literature concerns people's tendency to overestimate their own inputs (see Ross and Sicoly 1979) and that the interpretation of "deservingness" is often controversial (see Bazerman and Neale 1992). Both of these effects may be intensified under uncertainty.

\section{Experimental Setup}

In our experiment, randomly and anonymously paired subjects take on the role of department heads of a company who have to bargain over a salary budget. This salary budget is either completely or only to some extent determined by the department heads' joint performance in a real effort task. In addition, we vary the information about the relative performance of the department heads. Specifically, in the noinfo condition subjects receive no information on their relative or absolute performances in the real effort task, whereas in the info condition subjects get informed who in a pair had the better and who had the worse performance. In the deterministic (det) condition the salary budget is completely determined by department heads' joint performance, whereas in the stochastic (stoc) condition the salary budget is determined by department heads' joint performance only with a $25 \%$ chance and randomly determined with a chance of $75 \%$. Hence, we have a $2 \times 2$ experimental design with four treatments, which are labeled as noinfo-stoc, noinfo-det, info-stoc and, info-det.

At the beginning of the experiment, subjects are informed that their firm has a salary budget of 2050 points available and that this budget can change depending on their performances or some factors external to the firm. In any event, the top management of the firm does not want to impose a salary distribution. Instead, the department heads are asked to bargain over the distribution of the salary budget. ${ }^{5}$ In the experiment 100 points are worth 65 euro cents. Hence, the default salary budget of 2050 points corresponds to $€ 13,33$.

Table 1 summarizes the main elements of the experiment in the sequence they were presented to the subjects. ${ }^{6}$ Below, we explain each part in detail.

Performance and Outcome Determination: After reading the instructions aloud, the performance of each department head is determined with a general knowledge quiz (Hoffman et al. 1994; Clark 1998; Gächter and Riedl 2005). Before taking the quiz subjects are informed that their performances will affect the salary budget either for sure (in det) or with some chance (in stoc).

\footnotetext{
${ }^{5}$ This framing and some other details of the experimental design are borrowed from Gächter and Riedl (2005).

${ }^{6}$ After stage 7 we conducted another bargaining round, which was not pre-announced. The results of this stage are reported elsewhere.
} 
Table 1: Sequence of Events
1. Reading of instructions
2. Performance determination
3. Outcome determination
4. Elicitation of beliefs on performances
5. Relative performance information ${ }^{\dagger}$
6. Measurement of entitlements
7. Bargaining
8. De-briefing questionnaire

${ }^{\dagger}$ This information is given only in info condition

The general knowledge quiz consists of 16 multiple choice questions. For each question five possible answers are provided, with exactly one being the correct answer. The questions concern several fields of knowledge, such as politics, music, religion, astronomy and, geography. Each participant receives the same set of questions in the same order. Subjects have at most 30 seconds to answer each question. Unanswered questions count as wrong answers. The head of department with the most correct answers in each pair has a better performance. All subjects are informed of these details.

After the quiz, subjects get to know the actual salary budget, which could be 1390, 2050, or 2710 points. In the det condition, the salary budget is determined completely by the joint performances of department heads in a pair and described to subjects in the following way:

(i) If the total number of correct answers by you and the other department head is from 0 to 10 , then the salary budget will be 1390 points.

(ii) If the total number of correct answers by you and the other department head is from 11 to 20, then the salary budget will be 2050 points.

(iii) If the total number of correct answers by you and the other department head is from 21 to 32, then the salary budget will be 2710 points.

In the stoc condition, subjects are informed that with a chance of $25 \%$, their salary budget is determined by their joint performances and with a chance of $75 \%$ randomly, in which case each salary budget size has an equal chance to be chosen.

Elicitation of Beliefs on Performances: Knowing the salary budget, each subject is asked to report his or her beliefs about the own number of correct answers as well as the number of correct answers of the other department head. The rationale for asking subjects' beliefs about their 
performances after informing them about the value of the salary budget is that attributions may be reflected by these beliefs. These belief elicitations are incentivized: for each precise estimation, a subject earns 60 points, for each estimation with 1 (2) error(s), a subject earns 30 (15) points; estimates with larger errors do not earn any points.

Relative Performance Information: In the noinfo condition, subjects are not given any information about their relative performances in the quiz. In the info condition, they are given information indicating whether they are the better or worse performer in their pair. ${ }^{7}$ Specifically, the department head with more (less) correct answers in each pair receives a message saying that "You had more (less) correct answers in the general knowledge quiz than the other department head". In case of ties, subjects are also informed about that.

Measurement of Subjective Entitlements: We measure subjective entitlements of bargainers by an arbitrator question, adapted from Babcock, Loewenstein, Issacharoff and, Camerer (1995). All subjects answer the following question: ${ }^{8}$

"According to your opinion, what would be a 'fair' distribution of the salary budget from the vantage point of a non-involved neutral arbitrator? (Please use exact amounts; no intervals! The amounts have to sum up to the salary budget!)"

The answer given to this question informs us about subjective fairness judgments that are likely to influence bargaining behavior (cf. Gächter and Riedl 2005).

Bargaining: Subjects in each pair have to bargain over the available salary budget. Bargaining can take at most ten minutes and if subjects reach an agreement, they are paid their agreed shares. If they do not reach an agreement within ten minutes, they are 'fired' by the top management and do not earn any points from bargaining. Bargaining is free-form because it avoids exogenous first-mover effects and gives subjects as much bargaining freedom as possible (e.g., in the timing, sequence and number of proposals). Subjects are seated in computer cubicles and bargain anonymously over a computer network by sending proposals that consist of an amount for themselves and an amount for the other department head. Verbal communication is not allowed. ${ }^{9}$

\footnotetext{
${ }^{7}$ The rationale for presenting this information after eliciting beliefs on performances is two-fold. First, the salary budget information already reduces performance uncertainty and we did not want to present more information that might influence subjects' beliefs, and second, we did want to have a certain level of symmetry in belief elicitation between the info and noinfo conditions.

${ }^{8}$ Subjects were not informed about this question beforehand. They answered it after they stated their beliefs about performances in the noinfo condition and after they received the relative performance information in the info condition, respectively. Hence, subjects' fairness judgments may depend on the role (they believe) they are in. For this reason, we call this entitlements subjective.

${ }^{9}$ For bargaining instructions and a bargaining screen-shot, see the Appendix B.
} 
De-briefing Questionnaire: After all parts of the experiment are finished, subjects are asked to report their satisfaction about the bargaining outcome, their opinion about the quiz and their bargaining behavior. They are also presented the Machiavelli personality test (Christie and Geis 1970) to measure certain personality traits such as toughness, self-orientation, competitiveness, etc., which could be important in bargaining, and a risk attitude questionnaire (Dohmen et al. 2005). Finally, subjects answer a few questions about their personal background.

The experiment was computerized and programmed in z-Tree (Fischbacher 2007). We conducted the experiment in the BEElab (Behavioral and Experimental Economics laboratory) of Maastricht University in April 2009 and February 2010. In total 348 subjects participated in 16 randomized experimental sessions. Most of our subjects were undergraduates in economics, business and international business. A typical session lasted about 90 minutes. The average earnings per subject were approximately $€ 16$ (including a show-up fee of $€ 3$ ).

\section{Results}

We first present some descriptive statistics using the pooled data from all conditions and then move on to a more detailed analysis of important aspects of the bargaining process (that is, opening proposals, concessions, bargaining duration, agreements). In the analysis of the different conditions we focus on differences between the info and the noinfo conditions (aggregating over det and stoc) and the det and the stoc conditions (aggregating over info and noinfo). The reason for this focus is that it allows us to examine, on the one hand, the effect of performance information, and, on the other hand, the effect of uncertainty in the budget determination process. Thereafter, we relate differences in the bargaining process across different conditions to differential influences of subjective entitlements.

In what follows, we refer to the subject with more (less) correct answers in the general knowledge quiz as the "winner" ("loser") and express all allocations in shares to the winners ("winner share"). Throughout the paper, when referring to statistical tests, we use two-sided Mann-Whitney signed rank, Wilcoxon rank-sum, and Spearman rank-order correlation tests where appropriate and unless otherwise stated.

Overall, in 22 (out of 174) pairs both subjects had the same number of correct answers. On average, the fairness judgment of these subjects is 0.53. 19 of these pairs agreed on an equal division of the salary budget. Whenever we analyze winners' and losers' behavior (e.g., their fairness judgments, opening proposals etc.) we exclude these pairs from the analyzes. Furthermore, in regression analyzes where we use pair-level data (e.g., bargaining duration, concession behavior 
etc.) these pairs are included and their impact is controlled for with a dummy variable, tie. It takes the value 1 for pairs where both subjects had the same number of correct answers, and 0 otherwise.

\subsection{Descriptive Statistics}

The average number of correct answers in the quiz was 7 (out of 16). On average, subjects predicted that they had 7.26 correct answers and that the other department head had 7.54 correct answers $(p=0.015)$. That we do not observe overconfidence is in line with findings in other studies indicating that there is no (or negligible) overconfidence at success levels of around $50 \%$ (cf. Moore and Healy 2008; Blavatskyy 2009). Importantly, subjects' answers to the de-briefing questions about the quiz show that they perceive it as a legitimate measure of general knowledge, which is also confirmed by subjects' opinion on the difficulty of the quiz. ${ }^{10}$

The salary budget of 1390,2050 , and 2710 points occurred in 55, 81, and, 38 pairs, respectively. In the statistical analysis we pool all salary budget sizes because there are no significant differences with regard to any main behavioral aspects, as fairness judgments, bargaining duration, agreements, etc., across different budget sizes. ${ }^{11}$ Overall, the average duration of bargaining was 5.48 minutes and the average number of proposals in a pair was 11.6. Out of 174 bargaining pairs, 169 reached an agreement, with an average winner share (of the salary budget) of 0.53 . We exclude the five pairs which did not reach an agreement from our analyzes of agreement times and agreements.

\subsection{The Effects of Information and (Un)certainty on Bargaining Outcomes}

Opening Proposals: Figure 1 depicts the distribution of the very first proposals (opening proposals) made in a bargaining pair, separately for losers and winners in the pooled data. As the figure shows, winners' opening proposals are always at or to the right of 0.50 (mean 0.63) and losers' opening proposals are mostly at or to the left of 0.50 (mean 0.45 ). The equal-split (50-50) is the modal opening proposal of losers, who made an opening proposal in 26 out of 73 cases.

The share proposed in the very first offer clearly depends on the role the subject is in. In all four conditions, the opening proposals of winners are highly significantly larger than the opening proposals of losers $(p<0.0001)$. In addition, 11 (1) of 12 equal-split proposals in info came

\footnotetext{
${ }^{10}$ In a 7 -point Likert scale where " $1=$ do not agree at all" and " $7=$ agree very much", the average (median) degree of agreement with the statement "In my view the knowledge questions have been difficult" is 5.10 (5). On the same scale, the average (median) degree of agreement with the statement "The one with the better general knowledge is able to answer more questions correctly" is $5.42(6)$.

${ }^{11}$ Across all three salary budgets, Kruskal-Wallis rank tests fail to reject the null hypotheses of equality of fairness judgments of winners $(p=0.57)$ or losers $(p=0.93)$, bargaining durations $(p=0.60)$, and agreements $(p=0.54)$.
} 


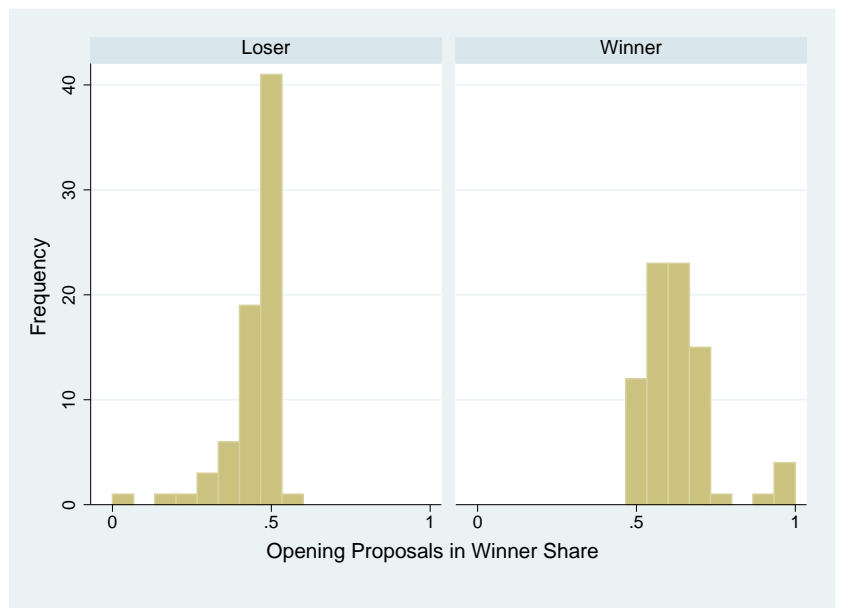

Figure 1: Distribution of Openining Proposals (pooled data)

from losers (winners) and 14 (3) of 17 equal-split opening proposals made in noinfo came from belief-losers (belief-winners). ${ }^{12}$

Table 2 shows the average opening proposals (in winner shares) by winners and losers in the different conditions and treatments. The results depicted in the table show that both the presence of relative performance information and the way the salary budget is determined cause differences in opening proposals. For winners and losers they are higher in the info condition than in the noinfo condition ( $p=0.0001$ for winners and $p=0.006$ for losers), and they are also higher in the det condition than in the stoc condition (winners: $p=0.1040$, losers: $p=0.003$ ). This indicates that whenever there is performance information or outcome certainty, winners' opening proposals become more aggressive and losers' opening proposals become more accommodating.

Concessions: We employ three concession indices introduced by Gächter and Riedl (2005), which incorporate both the size of a concession and the time at which a concession is made. These three measures are (i) the sum of average relative concessions, (ii) the sum of average concession times, and (iii) the sum of average time-weighted relative concessions, where the sum is taken over the individual statistics of the two bargainers in a pair. ${ }^{13}$ These indices combine individual-level data

\footnotetext{
${ }^{12}$ Belief-winners (belief-losers) are subjects whose predictions of number of own correct answers are greater (less) than their predictions of other department head's number of correct answers.

${ }^{13}$ The exact definitions are as follows (adapted from Gächter and Riedl 2005): A relative concession of a winner is defined as the difference between a winner's standing offer (in winner share) and his new offer (in winner share) divided by the current bargaining area. The current bargaining area is given by the difference between the standing offer of the winner (as winner share) and the standing offer of the loser (as winner share). A relative concession of a loser is defined analogously. For example, if the standing offers of a winner and a loser are 0.7 and 0.5 , respectively (i.e., the current bargaining area is 0.2 ), and the winner now demands only 0.6 for himself, then the absolute concession
} 
Table 2: Average Opening Proposals (Winners and Losers)

\begin{tabular}{|c|c|c|c|c|c|c|c|}
\hline & \multicolumn{3}{|c|}{ Winners } & & \multicolumn{3}{|c|}{ Losers } \\
\hline & noinfo & info & both & & noinfo & info & both \\
\hline \multirow{2}{*}{ stoc } & 0.59 & 0.64 & 0.61 & \multirow{2}{*}{ stoc } & 0.41 & 0.45 & 0.43 \\
\hline & $(20)$ & (18) & (38) & & $(23)$ & (19) & (42) \\
\hline \multirow{2}{*}{$\operatorname{det}$} & 0.60 & 0.69 & 0.66 & \multirow{2}{*}{ det } & 0.48 & 0.48 & 0.48 \\
\hline & (18) & $(23)$ & $(41)$ & & (17) & (14) & (31) \\
\hline \multirow{2}{*}{ both } & 0.59 & 0.67 & & \multirow{2}{*}{ both } & 0.44 & 0.46 & \\
\hline & $(38)$ & $(41)$ & & & $(40)$ & $(33)$ & \\
\hline
\end{tabular}

Note: Numbers in parentheses are the numbers of observations.

in each pair and summarize the concession behavior in a pair, which circumvents the problem of reciprocal behavior in bargaining when analyzing individual concession behavior (Kuon and Uhlich 1993; Hennig-Schmidt 1999).

Table 3 shows descriptive statistics for all three concession indices in all four conditions. Note, that a larger value of the sum of average relative concessions (relative-concession) indicates larger concessions, a larger value of the sum of average concession times (concession-time) indicates later concessions and, a larger value of the sum of average time-weighted relative concessions (timeweighted) indicates earlier and/or larger concessions.

The figures in the table show that, concessions in the noinfo condition are larger (relativeconcession $=1.06)$ and earlier (concession-time $=258.9$ ) compared to those in the info condition (0.75 and 420.0, respectively). The average time-weighted relative concessions are also larger in the noinfo condition (time-weighted $=512.3$ ) than in the info condition (284.6). All differences are statistically highly significant $(p \leq 0.0001)$. Qualitatively, the same relationships hold for all three

is 0.1 and the relative concession is $0.5(=0.1 / 0.2)$. The magnitude of 0.5 can be interpreted as going halfway toward an agreement. The initial bargaining area is assumed to be equal to the salary budget (i.e., 1). A concession leading to a new offer that precisely matches the opponent's standing offer gives a relative concession of 1 . Therefore, an acceptance is calculated as a relative concession of 1 . The summary statistics average relative concession of a bargainer is just the average of all of his relative concessions made during the bargaining process.

The average concession time of a bargainer is defined as the sum of concession times divided by the number of concessions.

A time-weighted relative concession is a relative concession (as defined above) multiplied by (600 time of concession) if the concession is positive and multiplied by time of concession if the concession is negative, respectively. This measure has the property that a given positive (negative) relative concession gets the less (more) weight the later the concession is made. The statistic we use is the average of all time-weighted relative concessions of a bargainer. 
Table 3: Average Concession Behavior in each Condition

\begin{tabular}{lcccc}
\hline \hline & noinfo & info & stoc & det \\
\cline { 2 - 5 } relative-concession & 1.06 & 0.75 & 0.94 & 0.87 \\
& $(0.50)$ & $(0.59)$ & $(0.60)$ & $(0.52)$ \\
concession-time & 258.9 & 420.0 & 300.5 & 376.5 \\
& $(219.1)$ & $(215.3)$ & $(209.4)$ & $(248.2)$ \\
time-weighted & 512.3 & 284.6 & 424.0 & 377.6 \\
& $(335.6)$ & $(369.4)$ & $(390.6)$ & $(345.8)$ \\
\hline
\end{tabular}

Note: Standard deviations in parentheses.

concession indices when comparing the stoc condition with the det condition. Here, the differences in concession-time and time-weighted concessions are also statistically significant $(p=0.0483$ and $p=0.0671$, respectively).

Bargaining Duration: The mean bargaining duration is 329 seconds, which is slightly more than half of the 600 seconds of bargaining time given to the subjects. Agreement times are widely dispersed (standard deviation: 232 seconds) and range from agreements already after 12 seconds to last-second agreements. Table 4 reports the distribution of agreements over time (in minute blocks). The statistics shown in table indicate that agreements are reached most frequently either at the very beginning or at the very end. 49 pairs (out of 169 pairs that reached agreements) agreed in the first two minutes. In the next seven minutes, only 57 pairs reached agreements, whereas the number of pairs that stroke an agreement in the last minute is 63.54 of these 63 last-minute agreements are reached in the last five seconds. This tendency to reach agreements in the last minute is in line with observations in many other free-form bargaining experiments (see, e.g., Roth et al. 1988).

Importantly, the frequency of last-minute agreements strongly varies across conditions. In the

Table 4: Distribution of Agreements over Time

\begin{tabular}{|c|c|c|c|c|c|c|c|c|c|c|}
\hline time blocks & $\underline{0-1}$ & $\underline{1-2}$ & $\underline{2-3}$ & $\underline{3-4}$ & $\underline{4-5}$ & $\underline{5-6}$ & $\underline{6-7}$ & $\underline{7-8}$ & $\underline{8-9}$ & $\underline{9-10}$ \\
\hline Pooled Data & 28 & 21 & 15 & 9 & 14 & 8 & 3 & 4 & 4 & 63 \\
\hline noinfo & 20 & 16 & 12 & 6 & 6 & 4 & 0 & 1 & 2 & 22 \\
\hline info & 8 & 5 & 3 & 3 & 8 & 4 & 3 & 3 & 2 & 41 \\
\hline stoc & 14 & 13 & 9 & 7 & 7 & 5 & 3 & 3 & 2 & 27 \\
\hline det & 14 & 8 & 6 & 2 & 7 & 3 & 0 & 1 & 2 & 36 \\
\hline
\end{tabular}


info condition they are almost twice as frequent as in the noinfo condition (41 vs. 22) and in the det condition they are more frequent than in the stoc condition (36 vs. 27). Tests of equality of proportions confirm that theses differences are statistically significant $(p=0.0002$ and $p=0.0184$, one-sided tests). The differences across conditions are also reflected in average bargaining durations. The average bargaining duration in the noinfo condition is 255 seconds whereas it takes subjects 424 seconds to strike an agreement in the info condition $(p<0.0001)$. Similarly, in the stoc condition, on average, an agreement is reached after 307 seconds but this takes, on average, 369 seconds in the det condition $(p=0.09)$. Hence, bargaining was tougher in info and det than in noinfo and stoc.

Agreements: Figure 2 depicts the distribution of agreements (in winner shares) across all conditions. It shows that although about half of all agreements (82 out of 169) are equal-splits, agreements are clearly twisted in favor of winners. On average, the agreed share to a winner is 0.53 and it is significantly greater than $0.50(p<0.0001)$. In 73 cases (out of 169$)$ the agreeed share to the winner is more than $50 \%$ of the available salary budget.

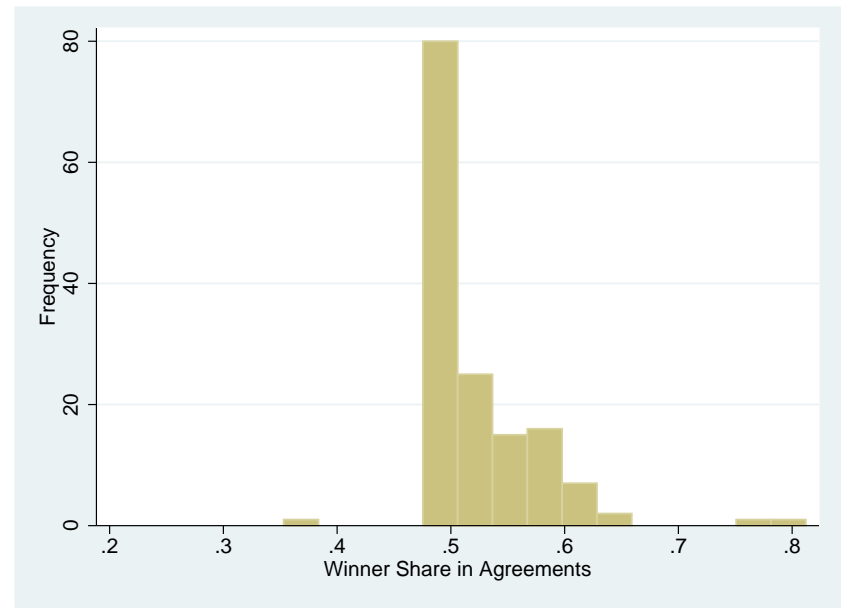

Figure 2: Disribution of Agreements (pooled data)

The pooled data conceal quite some differences in agreements across conditions, however. Figure 3 depicts the distribution of agreements (in winner shares) in the info and noinfo conditions (Panel (a)) and in the det and stoc conditions (Panel (b)), separately.

Figure 3(a) indicates a clear difference in agreements between the info and the noinfo condition. In noinfo all agreements are close to the equal split, whereas agreements in info they are mostly spread out between 0.5 and 0.65 . Equal splits occured only 17 times in the info condition, but 65 times in the noinfo condition. A test of equality of proportions shows that this difference is significant $(p<0.0001$, one-sided test). On average, the agreed share to the winner is 0.55 in 


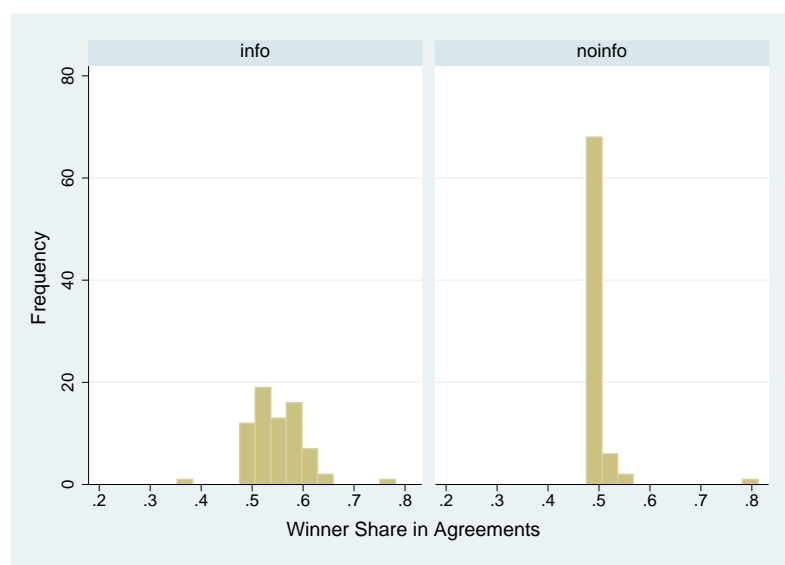

(a) info and noinfo conditions

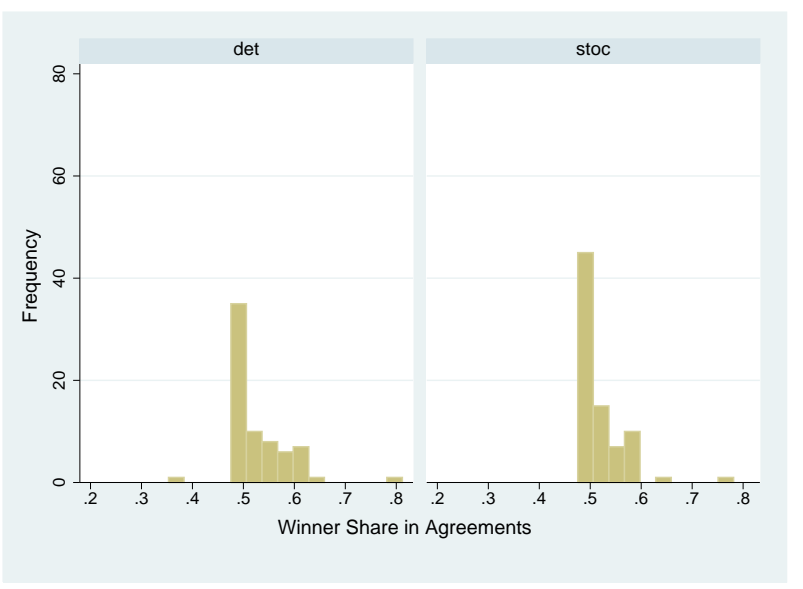

(b) det and stoc conditions

Figure 3: Distributions of Agreements in each Condition

the info condition, but only 0.51 in the noinfo condition. This difference is statitically significant $(p<0.001)$. Furthermore, in the info condition the average agreed share is signficantly larger than $0.50(p=0.000)$, whereas this is not the case in the noinfo condition $(p=0.7788)$.

Figure 3(b) suggests only little differences in agreements between the det and stoc conditions. Indeed, on average, the agreed share to the winner is 0.52 in condition stoc condition and 0.53 in condition det. These averages are significantly different from 0.50 in both conditions $(p<0.0001)$. However, the average agreed shares do not significantly differ between the two conditions $(p=$ $0.3786)$.

Table 5 summarize our main findings reported in this subsection.

Table 5: Significant Differences between Conditions

\begin{tabular}{ccc}
\hline \hline & \multicolumn{2}{c}{ difference between } \\
\cline { 2 - 2 } opening proposals & yes & det and inoinfo \\
\cline { 2 - 3 } concessions & yes & yes \\
duration & yes & yes \\
agreements & yes & yes \\
\hline
\end{tabular}




\subsection{Explaining Differences in Bargaining Outcomes}

We hypothesize that the influence of relative performance information and (un)certainty on bargaining behavior operates - at least to some extent - through derived subjective entitlements. In this subsection, we analyze the derived entitlements and examine the link between the differences in bargaining outcomes across conditions reported in the previous subsection and these entitlements.

\section{The Subjective Entitlements}

Figure 4 depicts the distribution of subjective entitlements (in winner shares) for winners and losers as measured by the answers to the arbitrator question. It shows that for winners as well as

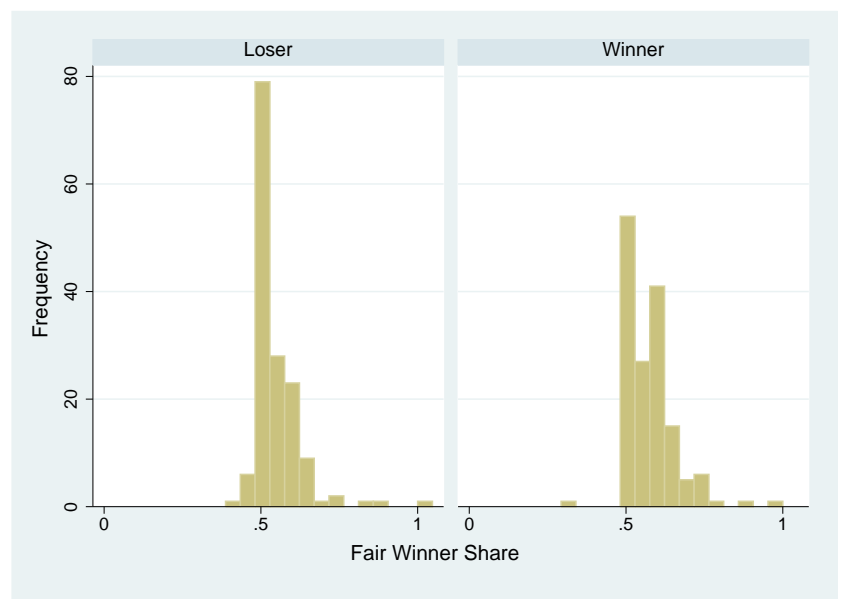

Figure 4: Distribution of Subjective Entitlements for Losers and Winners (pooled data)

losers subjective entitlements are skewed away from the equal split in favor of the winner. The average subjective entitlement of winners is 0.57 and of losers is 0.54 . This difference is statistically significant $(p=0.0001)$.

If relative performance information or certainty about the outcome lead to stronger entitlements for winners, we should observe winners' entitlements to be more skewed away from the equal split in info and det conditions than in noinfo and stoc, respectively. We also expect that entitlements are more inconsistent between winners and losers when there is information about the performance (info) or when it is certain that performance determines the salary budget (det) than when this is not the case.

Table 6 shows the average subjective entitlements of winners and losers in each treatment and condition. Winners' and losers' entitlements indeed differ systematically across conditions. In particular, the winner share of the salary budget winners believe to be fair is significantly higher in the info condition $(0.61)$ than in the noinfo condition $(0.54)(p<0.0001)$. In contrast, for losers average entitlements (in winner share) are significantly smaller in the info condition (0.53) than in 
the noinfo condition (i.e., 0.56) $(p=0.0207)$. On the other hand, there are no significant differences in subjects' entitlements between the stoc and the det conditions $(p=0.2831$ and $p=0.9364$ for winners and losers, respectively).

Table 6: Subjective Entitlements of Winners and Losers in each Condition

\begin{tabular}{|c|c|c|c|c|c|c|c|}
\hline & \multicolumn{3}{|c|}{ Winner } & & \multicolumn{3}{|c|}{ Losers } \\
\hline & noinfo & info & both & & noinfo & info & both \\
\hline \multirow{2}{*}{ stoc } & 0.53 & 0.59 & 0.56 & \multirow{2}{*}{ stoc } & 0.57 & 0.52 & 0.55 \\
\hline & $(43)$ & $(37)$ & $(80)$ & & $(43)$ & $(37)$ & (80) \\
\hline \multirow{2}{*}{ det } & 0.55 & 0.62 & 0.59 & \multirow{2}{*}{$\operatorname{det}$} & 0.54 & 0.53 & 0.54 \\
\hline & $(35)$ & $(37)$ & $(72)$ & & $(35)$ & $(37)$ & (72) \\
\hline \multirow{2}{*}{ both } & 0.54 & 0.61 & & \multirow{2}{*}{ both } & 0.56 & 0.53 & \\
\hline & $(78)$ & $(74)$ & & & (78) & $(74)$ & \\
\hline
\end{tabular}

Note: Numbers of observations in parentheses.

The observed differences in subjective entitlements across conditions between winners and losers clearly suggest a role-specific self-serving bias. As already reported above, for the pooled data, when comparing entitlements of winners and loser we find a small (3 percentage points) but statistically significant self-serving bias ( $p=0.0001)$. For individual conditions, we observe a larger self-serving bias in info and det. In the info condition the difference between winners' and losers' subjective entitlements amounts to 7.8 percentage points $(p<0.0001)$, and in condition det it amounts to 4.7 percentage points $(p=0.0006)$. There are no significant differences in entitlements between winners and loser in the noinfo and stoc conditions. The non-existence of a self-serving bias in the noinfo condition is hardly surprising, because subjects had no information about their relative performance. However, on an individual level there may be some relation between the beliefs about ones relative performance and derived subjective entitlements. To analyze this we use the elicited beliefs about the number of correct answers in the quiz to examine if there is a self-serving bias present for those who believed that they were the winners or losers. In the noinfo condition, the subjective entitlements of such belief-winners is 0.56 and that of belief-losers is 0.54 . The difference is small and not significant ( $p=0.1548)$.

\section{The Role of Subjective Entitlements in the Bargaining Process and Outcome}

In subsection 4.2 , we have seen that with relative performance information (info) or outcome certainty (det) bargaining was tougher and that agreements differed across conditions. We now examine if these differences in the bargaining process and outcome are mediated through subjective entitlements. Specifically, in comparison to the noinfo and stoc conditions, we expect a stronger 
correlation in conditions info and det, between subjective entitlements and (i) opening proposals, (ii) concessions, (iii) bargaining duration and, (iv) agreements.

Opening Proposals: Opening proposals are likely influenced not only by entitlements but also by strategic considerations. The data are indeed consistent with this idea. In all conditions, winners' opening proposals are higher than their entitlements, whereas losers' opening proposals are lower than their entitlements. These differences are statistically significant for winners and losers in all conditions $(p \leq 0.0111)$.

Table 7: Subjective Entitlements and Opening Proposals in each Condition

\begin{tabular}{lccccccccc}
\hline \hline & \multicolumn{4}{c}{ Winners } & & \multicolumn{4}{c}{ Losers } \\
\cline { 2 - 3 } & noinfo & info & stoc & det & & noinfo & info & stoc & det \\
\hline subjective entitlement & 0.54 & 0.61 & 0.56 & 0.59 & & 0.56 & 0.53 & 0.55 & 0.54 \\
opening proposal & 0.59 & 0.67 & 0.61 & 0.66 & & 0.44 & 0.46 & 0.43 & 0.48 \\
difference & 0.05 & 0.06 & 0.05 & 0.07 & & -0.12 & -0.07 & -0.12 & -0.06 \\
\hline
\end{tabular}

Note: difference $=$ average opening proposal - average subjective entitlement.

We also find that the differences between opening proposals and subjective entitlements are different across conditions. If entitlements matter, we should see a positive relationship between them and the opening proposals. In addition, as argued above, we expect this effect to be stronger in the info condition than in the noinfo condition, and in the det condition than in the stoc condition.

Table 8 reports robust Tobit regression results, where we regress the opening proposals on subjective entitlements of winners and losers, separately for each condition. In line with our hypotheses the coefficient estimates for winners' subjective entitlement (denoted $W_{-}$Fair) are positive and statistically significant in conditions info, det and, stoc $(p<0.036)$. Hence, in these conditions, winners' opening proposals are significantly and positively affected by their subjective entitlements. In contrast, losers' entitlements (denoted L_Fair) are not significant in the info, noinfo, and det conditions and significant with the wrong sign in condition stoc $(p=0.011)$. Our interpretation of these results is that fairness judgments did not influence losers behavior in a systematic way. Subjective entitlements did also not affect opening proposals of winners in the noinfo condition, indicating that entitlements are only important when they can be related to the role one has according to the performance measure.

Concession Behavior: We know that information on the relative performance of department heads as well as certainty regarding the process of the salary budget determination lead to smaller and later concessions (cf. Subsection 4.2), and that it also increases the difference in winners' and losers' 
Table 8: Explaining Opening Proposals in each Condition

\begin{tabular}{|c|c|c|c|c|c|c|c|c|}
\hline & \multicolumn{8}{|c|}{ Dependent Variable: opening share to winner } \\
\hline & \multicolumn{2}{|c|}{ noinfo } & \multicolumn{2}{|c|}{ info } & \multicolumn{2}{|c|}{ stoc } & \multicolumn{2}{|c|}{$\operatorname{det}$} \\
\hline & Winner & Loser & Winner & Loser & Winner & Loser & Winner & Loser \\
\hline \multirow{2}{*}{ Constant } & $0.41^{* * *}$ & $0.49^{* * *}$ & 0.26 & $0.38^{* * *}$ & 0.28 & $0.76^{* * *}$ & 0.23 & $0.38^{* * *}$ \\
\hline & $(0.14)$ & $(0.12)$ & $(0.15)$ & $(0.09)$ & $(0.16)$ & $(0.13)$ & $(0.12)$ & $(0.07)$ \\
\hline \multirow{2}{*}{$W$-Fair } & 0.34 & & $0.67^{* * *}$ & & $0.58^{* *}$ & & $0.74^{* * *}$ & \\
\hline & $(0.23)$ & & $(0.24)$ & & $(0.27)$ & & $(0.21)$ & \\
\hline \multirow{2}{*}{$L$-Fair } & & -0.08 & & 0.19 & & $-0.61^{* *}$ & & 0.19 \\
\hline & & $(0.21)$ & & $(0.16)$ & & $(0.23)$ & & $(0.11)$ \\
\hline $\log -L$ & 28.8 & 52.64 & 34.8 & 41.2 & 34.9 & 34.3 & 29.1 & 45.0 \\
\hline$F$ & 2.18 & 0.13 & $8.09^{* * *}$ & 1.53 & $4.72^{* *}$ & $7.12^{* *}$ & $12.01^{* * *}$ & 3.06 \\
\hline$N$ & 38 & 40 & 41 & 33 & 38 & 42 & 41 & 31 \\
\hline
\end{tabular}

Note: ${ }^{* * *}\left({ }^{* *}\right)$ indicates $1 \%(5 \%)$ significance level; robust standard errors in parentheses. 
subjective entitlements (cf. Subsection 4.3). We hypothesize that these differences in concession behavior across conditions are influenced by derived entitlements. Thus, we should find a stronger effect of entitlements in the info condition in comparison to the noinfo condition and in the det condition in comparison to the stoc condition.

In Table 9 we report robust Tobit estimates where we regress our most encompassing concession measure, the time-weighted concessions, on the tension in subjective entitlements between winners and losers, denoted as Diff_Fair. ${ }^{14}$ The results for the other two concession measures, relativeconcession and concession-time are qualitatively the same and reported in Table A1 in Appendix A. The regression results show a strong influence of the tension in subjective entitlements in conditions info and det in the expected direction ( $p<0.001$ for both). Hence, if it is known who the better performer was and/or if it is known that joint performance determined the salary budget with certainty, then the further apart the subjective entitlements of winners and loser are the less conceding a bargaining pair appears. There is no such significant influence of subjective entitlements in the other two conditions.

Table 9: Explaining Concessions in each Condition

\begin{tabular}{|c|c|c|c|c|}
\hline & \multicolumn{4}{|c|}{ Dependent Variable: time-weighted concessions } \\
\hline & noinfo & info & stoc & det \\
\hline \multirow{2}{*}{ Constant } & $512.7^{* * *}$ & $329.6^{* * *}$ & $431.5^{* * *}$ & $391.6^{* * *}$ \\
\hline & $(45.3)$ & $(55.5)$ & $(49.7)$ & $(42.3)$ \\
\hline \multirow{2}{*}{ Diff_Fair } & -3.60 & $-889.3^{* * *}$ & -486.1 & $-888.7^{* * *}$ \\
\hline & $(313.4)$ & $(296.7)$ & $(318.0)$ & $(257.5)$ \\
\hline \multirow{2}{*}{ Tie } & 120.7 & 130.7 & 105.6 & 160.6 \\
\hline & $(88.4)$ & $(99.2)$ & $(85.5)$ & $(112.7)$ \\
\hline $\log -L$ & -649.7 & -602.8 & -668.9 & -587.4 \\
\hline$F$ & 0.94 & $6.09^{* * *}$ & 2.16 & $6.28^{* * *}$ \\
\hline$N$ & 90 & 84 & 91 & 83 \\
\hline
\end{tabular}

Note: ${ }^{* * *}$ indicates $1 \%$ significance level; robust standard errors in parentheses. Tie equals 1 if both department heads had the same performance, 0 otherwise.

Bargaining Duration: We observed significant differences in average agreement times between info and noinfo, one the one hand, and between det and stoc, on the other hand (cf. Subsection 4.2).

\footnotetext{
${ }^{14}$ Diff_Fair is equal to $W_{-}$Fair - L_Fair. It is positive when there are inconsistent entitlements and negative (or zero) when there are consistent entitlements in a pair.
} 
In the following, we examine whether these differences across conditions are due to a differential influence of entitlements in the different conditions. Similarly to concessions, we expect bargaining duration to be correlated with the tension in subjective entitlements of winners and losers in a pair (i.e., Diff_Fair). The stronger this tension, the longer bargaining should take. In addition, the effect of entitlements should be stronger in info than in noinfo and stronger in det than in stoc.

Table 10 reports robust Tobit regression results where we regress bargaining duration on the difference in subjective entitlements, in each condition. Note first, that if both department heads

Table 10: Explaining Bargaining Duration in each Condition

\begin{tabular}{|c|c|c|c|c|}
\hline & \multicolumn{4}{|c|}{ Dependent Variable: bargaining duration } \\
\hline & noinfo & info & stoc & det \\
\hline \multirow{2}{*}{ Constant } & $272.1^{* * *}$ & $389.6^{* * *}$ & $324.0^{* * *}$ & $360.7^{* * *}$ \\
\hline & $(26.4)$ & $(33.8)$ & $(25.3)$ & $(29.6)$ \\
\hline \multirow{2}{*}{ Diff_Fair } & 37.9 & $799.4^{* * *}$ & 358.5 & $705.1^{* * *}$ \\
\hline & $(222.2)$ & $(257.2)$ & $(228.3)$ & $(203.0)$ \\
\hline \multirow{2}{*}{ Tie } & $-140.5^{* * *}$ & $-195.9^{* * *}$ & $-167.5^{* * *}$ & $-186.5^{* * *}$ \\
\hline & $(51.5)$ & $(54.1)$ & $(47.6)$ & $(65.7)$ \\
\hline $\log -L$ & -600.1 & -516.4 & -603.3 & -522.6 \\
\hline$F$ & $3.72^{* *}$ & $21.78^{* * *}$ & $11.32^{* * *}$ & $8.28^{* * *}$ \\
\hline$N$ & 89 & 80 & 90 & 79 \\
\hline
\end{tabular}

have the same performance, i.e. if there is no winner (and loser), bargaining duration is significantly shorter in all conditions (cf. the significant coefficients of Tie). Second, and more important, the coefficients for Diff_Fair have the expected sign in all conditions, but are significant only ininfo and $\operatorname{det}(p=0.003$ and $p=0.001$, respectively). Hence, as hypothesized the subjective entitlements of winners and losers strongly influence bargaining duration in condition info and det only, which indicates that the difference in bargaining duration between conditions is strongly due to a differential influence of these entitlements.

As reported in Subsection 4.2, we observe a large number of last-minute agreements. In addition, the frequency of such last-minute agreements was much larger in the info condition than in the noinfo condition, whereas the difference between conditions det and stoc was only marginally significant. Hence, it is natural to ask if subjective entitlements also play a role here, or if late 
agreements are solely due to strategic considerations as reported in Roth et al. (1988) and argued by Fershtman and Seidmann (1993). To examine this we compare the tension in entitlements (i.e., Diff_Fair) in pairs that reached agreements in the last minute with those in pairs that reached agreements before the last minute.

In the info condition, the difference in entitlements for pairs that reached agreements in the last minute is 9.5 percentage points whereas it is only 3.4 percentage points for pairs that reached agreements before the last minute $(p=0.0001)$. In contrast, in the noinfo condition, there is no significant difference $(p=0.6339)$. Hence, the difference in last-minute agreements between these two conditions is likely to be affected by a differential influence of entitlements in these conditions. In the det and stoc conditions the differences in tension in entitlements between early an late agreeing bargaining pairs are significant $(p=0.0007$ and $p=0.003)$, which is consistent with the observed small difference in frequencies of early and late agreements in these conditions.

Overall, we can conclude that relatively small tensions in subjective entitlements made a substantial impact on bargaining duration in conditions info and det.

Agreements: Finally we examine whether subjective entitlements influence agreements and if this influence differs across conditions. As reported in Subsection 4.2, we observe unequal agreements more often in the info and det conditions than in the noinfo and stoc conditions, respectively. Hence, we hypothesize that the effect of subjective entitlements on agreements is strongest, or perhaps even only observable, in the info and det conditions. Figure 5 plots the relationships between winners' subjective entitlements (horizontal axes) and the agreed share to winners (vertical axes) in the info and noinfo conditions (Panel (a)) and the det and stoc conditions (Panel (b)). Figure 5(a)

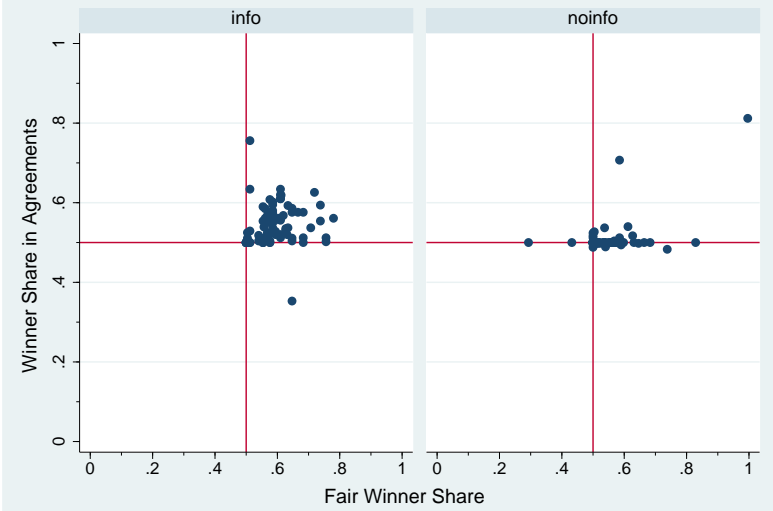

(a) info and noinfo conditions

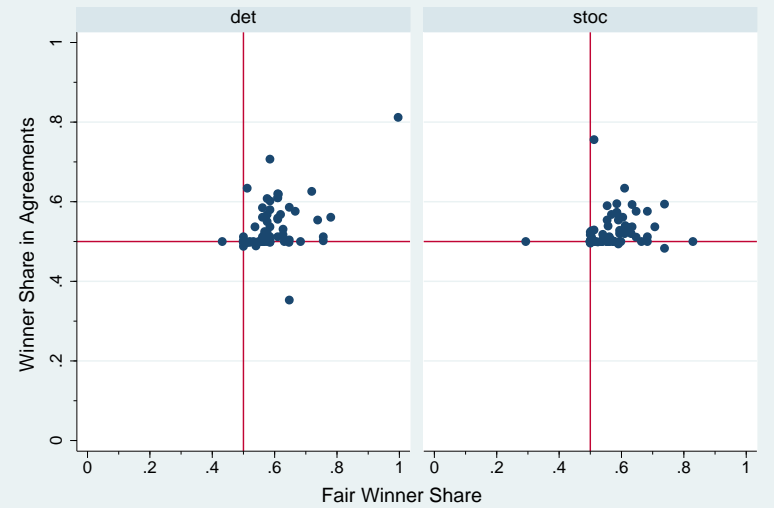

(b) det and stoc conditions

Figure 5: Agreements and Subjective Entitlements 
suggests a positive relationship between subjective entitlements and agreed winner shares in info (Spearman's $\rho=0.38, p=0.0005$ ) but no such relationship in noinfo (Spearman's $\rho=-0.03$, $p=0.7741)$. Figure 5(b) suggests a positive relationship between subjective entitlements and agreed shares to winners in condition $\operatorname{det}$ (Spearman's $\rho=0.53, p=0.0000$ ) and stoc (Spearman's $\rho=0.39, p=0.0001)$.

Table 11 reports robust Tobit regression results where we regress agreements on winners' and losers' subjective entitlements, in each condition. The coefficient estimates for winners' subjective entitlements ( W_Fair) are positive but statistically insignificant in conditions noinfo and info. In contrast, it is highly significant in conditions $\operatorname{det}(p=0.000)$ and stoc $(p=0.038)$. The coefficient estimates for the losers' fairness judgments (L_Fair) are positive and statistically significant in condition $\operatorname{det}(p=0.005)$. In all other cases they are insignificant. These regression results indicate that the subjective entitlements make the strongest impact on agreements when the surplus production is deterministic. Surprisingly, given the results on opening offers, concessions, and bargaining duration, entitlements seem not to have a significant influence on agreements in the info condition. However, when we exclude some subjects who could be interpreted as being outliers, the

Table 11: Explaining Agreements in each Condition

\begin{tabular}{ccccc}
\hline \hline & \multicolumn{4}{c}{ Dependent Variable: agreed share } \\
\cline { 2 - 5 } noinfo & info & stoc & det \\
\hline \multirow{2}{*}{ Constant } & $0.30^{* * *}$ & $0.49^{* * *}$ & $0.50^{* * *}$ & 0.13 \\
& $(0.10)$ & $(0.06)$ & $(0.04)$ & $(0.09)$ \\
W_Fair & 0.26 & 0.01 & $0.11^{* *}$ & $0.37^{* * *}$ \\
& $(0.16)$ & $(0.10)$ & $(0.05)$ & $(0.09)$ \\
L_Fair & 0.11 & 0.12 & -0.07 & $0.35^{* * *}$ \\
& $(0.07)$ & $(0.10)$ & $(0.04)$ & $(0.12)$ \\
Tie & 0.01 & $-0.05^{* * *}$ & $-0.02^{* * *}$ & 0.01 \\
& $(0.02)$ & $(0.01)$ & $(0.01)$ & $(0.02)$ \\
Log-L & 178.5 & 129.2 & 169.4 & 132.3 \\
$F$ & 1.37 & $26.01^{* * *}$ & $9.52^{* * *}$ & $8.00^{* * *}$ \\
$N$ & 89 & 80 & 90 & 79 \\
\hline $\begin{array}{l}\text { Note: } \\
\text { errors in parentheses. }\end{array}$ & Tie (5\%) significance level; robust standard \\
the same performance, 0 otherwise.
\end{tabular}


Table 12: Explaining Equal Splits in each Condition

\begin{tabular}{ccccc}
\hline \hline & \multicolumn{4}{c}{ Dependent Variable: equal split } \\
\cline { 2 - 5 } noinfo & info & stoc & det \\
\hline \multirow{2}{*}{ W_Fair } & $-1.57^{* * *}$ & -1.19 & $-3.78^{* * *}$ & $-5.71^{* * *}$ \\
& $(0.63)$ & $(0.62)$ & $(1.16)$ & $(1.40)$ \\
L_Fair & -0.62 & -1.04 & 0.43 & -1.91 \\
& $(0.56)$ & $(0.88)$ & $(0.76)$ & $(1.09)$ \\
Tie & 0.16 & -- & -- & $0.38^{* * *}$ \\
& $(0.10)$ & -- & -- & $(0.14)$ \\
Log-pseudo-L & -47.9 & -21.8 & -46.8 & -36.0 \\
Wald $\chi^{2}$ & $10.4^{* *}$ & $6.83^{* *}$ & $10.79^{* * *}$ & $23.67^{* * *}$ \\
N & 89 & 71 & 79 & 79 \\
\hline
\end{tabular}

Note: ${ }^{* * *}\left({ }^{* *}\right)$ indicates $1 \%(5 \%)$ significance level; robust standard errors in parentheses. Tie equals 1 if both department heads had the same performance, 0 otherwise; in info and stoc, Tie predicted the variation in the dependent variable perfectly and is therefore dropped.

coefficient estimate of $W_{-}$Fair in info takes on the value, 0.18 and becomes statistically significant at the $5 \%$ level $(p=0.049) \cdot{ }^{15}$

In Subsection 4.2 we report that 82 out of 169 agreements are equal splits. This suggests an alternative way of looking at agreements, namely asking for the determinants of equal splits. In Table 12, we report the results of robust Probit estimates where we regress the binary variable equalsplit, which takes on the value 1 for an equal split and 0 otherwise, on $W_{-}$Fair, L_Fair and Tie. As expected, winners' entitlements ( $W_{-}$Fair) have a negative impact on the probability of observing an equal-split. This effect is most prevalent in condition det. The variable Tie is dropped in conditions info and stoc because it predicts the variation perfectly and is statistically significant with the expected sign in condition $\operatorname{det}(p=0.011)$.

Overall, we find that subjective entitlements affect agreements. This holds especially for the subjective entitlements winners hold. The strength of their influence differs across conditions and is most prevalent in the condition where it is certain that the joint performance of department heads determine the salary budget. Interestingly, and in contrast to the entitlements' influence on opening offers, concessions, and bargaining duration, subjective entitlements have only limited influence on

\footnotetext{
${ }^{15}$ In the alternative regression five subjects (all winners) are excluded. One of them, despite being a winner, accepted a share of less than 0.40. Another one reported a subjective entitlement of about $50 \%$ but received a share larger than 0.75 , and three others reported extreme subjective entitlements larger than $75 \%$.
} 
agreements in the info condition. Nevertheless, the presented evidence strongly suggests that differences in agreements across the different conditions are mediated by subjective entitlements.

\subsection{The role of beliefs, personality traits, risk attitudes, and gender}

Subjects' Beliefs on Performances: In the noinfo condition subjects do not receive relative performance information, which raises the question of the importance of their beliefs on performances. Here we report subjects' beliefs and briefly discuss their influence on subjects' entitlements and bargaining behavior. In condition noinfo there are 33 (48) winners (losers) who also believe that they were winners (losers) and 18 (12) winners (losers) who believe that they were losers (winners). Actual winners, on average, predict that they have 8.36 correct answers and that their opponents have 8 correct answers $(p=0.0472)$. Actual losers, on average, predict that they have 7.10 correct answers and that their opponents have 8.18 correct answers $(p=0.0000)$. These results indicate that subjects' predictions are pretty accurate.

If subjects' beliefs on performances have an influence on entitlements one would expect that the predictions for their own performance are positively correlated with these entitlements (in winner share) for belief-winners and negatively correlated for belief-losers. We only find a significantly positive correlation for belief-winners (Spearman's $\rho=0.3855, p=0.0048$ ), whereas for belieflosers the correlation is negative but insignificant (Spearman's $\rho=-0.04, p=0.690$ ).

We also investigate whether beliefs played a role in the bargaining process. In particular, in condition noinfo beliefs on performances may be important because in this condition subjects receive no performance information. To investigate this we re-run the regression analyzes reported in Tables 8, 9, 10, and 11 but replaced actual winners and losers with belief-winners and belief-losers in the noinfo condition. We do not find any significant changes in results.

In our analyses of beliefs in other conditions (i.e., info, det, and stoc) we find that as far as the bargaining process is concerned, subjects' beliefs on performances have an influence only on opening proposals and only when the surplus production is deterministic. In this condition, on average, a belief-winner's opening proposal is 0.62 and a belief-loser's opening proposal is 0.57 , where the difference is marginally significant $(p=0.0622)$. Concessions, bargaining duration and agreements are not influenced by subjects' beliefs on performances.

Personality Traits and Risk Attitudes: As mentioned in Section 3, we included post-experimental questionnaires to obtain information about individual characteristics that may influence bargaining behavior. To examine whether these characteristics indeed exert any influence on bargaining behavior, we re-run the reported robust Tobit regression, by including Machiavelli personality test scores, risk attitude questionnaire scores, gender, income, and age as additional explanatory vari- 
ables. We do not find any significant effects of these variables in explaining opening proposals, concessions, bargaining duration, or agreements.

Gender Pairing Effects on Bargaining Outcomes: Some studies suggest gender effects in bargaining (see, e.g., Ayres and Siegelman 1995; Walters et al. 1998; Stuhlmacher and Walters 1999; Ben-Ner et al. 2004, Sutter et al. 2009). Therefore, we also examine more closely whether gender and/or gender-pairing affects bargaining outcomes. Before reporting direct effects we examine other factors that may differ between genders and, hence, may exert an indirect influence on bargaining behavior. First, we find that subjects' predictions about their performance in the real effort task differ between male and female subjects. On average, male subjects overestimate their number of correct answers in the quiz by 0.6 answers, while female subjects underestimate their performance by 0.06 answers. This small difference in predictions across genders is statistically significant $(p=0.03)$. There is also a significant difference between male and female subjects' predictions of their opponent's performance. Male subjects overestimate other subject's performance by 0.82 and female subjects overestimate other subject's performance by 0.23 . The difference between these two figures is also significant $(p=0.0638)$. Second, we find no gender difference in subjective entitlements: male winners' (losers') average fairness judgment amounts to 0.58 (0.56) and female winners' (losers') average fairness judgment is $0.57(0.54)$. The difference between male and female subjects is not significant, neither for winners $(p=0.5365)$ nor for losers $(p=0.4597)$. Finally, on average, in bargaining agreements male and female subjects (winners and losers) receive the same shares.

Interestingly, gender differences become more pronounced when looking at gender pairings instead of individuals' gender. ${ }^{16}$ The average difference between winners' and losers' fairness judgments in female-female pairs (0.02) and male-male pairs (0.03) do not significantly differ $(p=0.4108)$. However, on average the difference between first proposals in a pair significantly differ across female-female $(0.11)$ and male-male $(0.26)$ pairs $(p=0.0000)$. In comparison to male-male pairs, in female-female pairs relative concessions are larger, concession times are much earlier and, time-weighted relative concessions are much larger (male-male relative-concessions: 0.73, female-female relative-concessions: $1.12, p=0.0151$; male-male concession-time: 406.7, female-female concession-time: 242.4, $p=0.0018$; male-male time-weighted concessions: 262.4, female-female time-weighted concessions: $551.8, p=0.0018)$. Moreover, in female-female pairs, the average bargaining duration is much shorter (235.3 seconds) than in male-male pairs (403.7 seconds) $(p=0.0009)$. However, the average winner's share in agreements is almost identical in

\footnotetext{
${ }^{16}$ Note that in our experiment subjects do not know their opponent's gender. Moreover, with 180 female and 168 male subjects, we have a very balanced sample with respect to gender. Therefore, the probability of having a male or a female opponent is almost equal. In contrast, in Sutter et al. (2009), all subjects know the opponent's gender.
} 
female-female and male-male pairs (0.525 in female-female pairs: 0.525, male-male pairs: 0.523; $p=0.3263)$.

Subjects' Behavior as They Explain It: In the post-experimental questionnaire we asked subjects some questions about their behavior in the experiment. Most subjects gave detailed answers to these questions. Here, we briefly summarize subjects' answers to the question, "Which factors influenced your bargaining behavior?". The answers can be categorized in to four major groups emphasizing, (i) the importance of relative performance information (by far the largest group), (ii) the (un)certainty in the surplus production process, (iii) the focalness and/or fairness of the equalsplit, and (iv) strategic concerns, such as making an unchanging sequence of proposals, influencing opponent's aspirations, taking strong positions, testing the opponent's risk attitude, and waiting until the last seconds etc. (see, e.g., Schelling 1956; Sebenius 1992). It is interesting and consistent with our data on behavior that all winners mentioned the relative performance information as an important factor influencing their behavior. In addition, almost all losers also mentioned the relative performance information as a factor influencing their behavior. This suggests that losers felt some obligations which were, next to the entitlements of winners, also important in the bargaining process. Furthermore, in the noinfo and stoc conditions, a considerable number of subjects mentioned the unavailability of performance information and the presence of uncertainty as factors influencing their behavior.

\section{Concluding Remarks}

In this paper we investigate how bargaining about a jointly produced surplus is affected by relative performance information and randomness in the production process. In addition, we examine how subjective entitlements influence the bargaining process under the different conditions regarding relative performance information and noisy production. There is little doubt that subjects in our experiment adjust their entitlements and bargaining behavior to the external conditions. Specifically, the presence of relative performance information and the knowledge that the surplus production is free of random factors significantly influences almost all layers of the bargaining process as well as derived subjective entitlements. The effect of performance information is to some extent surprising because (i) the actual information given is very coarse - subjects only learn if they are the better or worse performer -, (ii) no explicit property right is given to better performers (as opposed to e.g. Hoffman et al. 1994), (iii) no potential anchoring point is presented to the subjects (as opposed to Gächter and Riedl 2005), and (iv) subjects did not believe that they performed very well in the real effort task determining the joined surplus. Uncertainty about the surplus production also has influence on bargaining behavior. The (un)certainty in surplus production significantly influenced 
opening proposals, concessions, bargaining duration and the likelihood of last-minute agreements. Interestingly, despite the fact that there are no significant differences between agreements (and fairness judgments) across the det and stoc conditions, we find that (un)certainty influenced agreements through the entitlements channel.

We find strong evidence that the differences in the bargaining process and bargaining outcomes across conditions are mediated by a differential impact of subjective entitlements on bargaining behavior. This shows that even economically irrelevant entitlements can influence bargaining behavior. The entitlements exert the strongest impact when the production process is deterministic and when there is relative performance information. These influences are in effect for opening proposals, concession behavior and bargaining duration, where stronger entitlements reduce subject's inclination to concede and lead to later agreements. Agreements are also influenced by entitlements of better performers (and sometimes by those of worse performers) in the real effort task. Especially, when the production process is deterministic these entitlements work in favor of better performer, in the sense that (s)he receives a larger share of the surplus. In addition, in all circumstances, stronger entitlements of better performers strongly decrease the likelihood of equal splits. Interestingly, beliefs about their own performance do exert some influence on entitlements and opening proposals but not to play a role in the rest of the bargaining process.

Our findings suggest an interesting and important interaction between relative performance information, uncertainties in the surplus production process and subjective - economically irrelevant - entitlements. When entering negotiations agents bring their entitlements to the bargaining table, but how these entitlements enter bargaining behavior crucially depends on the details of and the information on the production process. 


\section{References}

[1] Admati, A., M. Perry. 1987. Strategic delay in bargaining. Rev. Econ. Stud. 54(3) 345-364.

[2] Ayres, I., P. Siegelman. 1995. Race and gender discrimination in bargaining for a new car. Am. Econ. Rev. 85(3) 304-321.

[3] Babcock, L., G. Loewenstein. 1997. Explaining bargaining impasse: the role of self-serving biases. J. Econ. Perspect. 11(1) 109-126.

[4] Babcock, L., X. Wang, G. Loewenstein. 1996. Choosing the wrong pond: Social comparisons in negotiations that reflect a self-serving bias. Q. J. Econ. 111(1) 1-19.

[5] Babcock, L., G. Loewenstein, S. Issacharoff, C. Camerer. 1995. Biased judgments of fairness in bargaining. Am. Econ. Rev. 85(5) 1337-1343.

[6] Babcock, L., G. Loewenstein, X. Wang. 1995. The relationship between uncertainty, the contract zone, and efficiency in a bargaining experiment. J. Econ. Behav. Organ. 27(3) 475-485.

[7] Bazerman, M. H., M. A. Neale. 1992. Negotiating Rationally. Free Press, New York.

[8] Ben-Ner, A., F. Kong, L. Putterman. 2004. Share and share alike? Intelligence, socialization, personality, and gender-pairing as determinants of giving. J. Econ. Psychol. 25(5) 581-589.

[9] Blavatskyy, P. R. 2009. Betting on own knowledge: Experimental test of overconfidence. J. Risk Uncertainty 38(1) 39-49.

[10] Buhayar, N. 2009. The art of cutting pay, not people. http://www.bnet.com. (July 22).

[11] Camerer, C., G. Loewenstein. 1993. Information, fairness and efficiency in bargaining. Barbara A. Mellers, Jonathan Baron, eds. Psychological Perspectives on Justice. Theory and Applications. Cambridge University Press, Cambridge, U.K.,155-179.

[12] Christie, R. 1970. Scale construction. In: R. Christie and F. Geis, Editors, Studies in Machiavellianism, Academic Press, New York 10-33.

[13] Clark, J. 1998. Fairness in public good provision: an investigation of preferences for equality and proportionality. Can. J. Econ. 31(3) 708-729.

[14] Corfman, T. A., J. Schmeltzer. 2002. UAL machinists reject cuts. All other unions OK lower wages. Chicago Tribune. Online edition, (December 28). 
[15] Diekmann, K. A., Z. I. Barsness, H. Sondak. 2004. Uncertainty, Fairness Perceptions, and Job Satisfaction: A Field Study. Soc. Justice Res. 17(3) 237-255.

[16] Dohmen, T., A. Falk, D. Huffman, U. Sunde, J. Schupp, G. G. Wagner. 2005. Individual Risk Attitudes: New Evidence from a Large, Representative, Experimentally-Validated Survey. IZA Discussion Papers 1730.

[17] Donovan, J. 1998. League at a crossroads. CNN, Sports Illustrated, http://sportsillustrated.cnn.com/basketball/nba/1998/labor/news/1998/06/24/lockout/.

[18] Fershtman, C., D. J. Seidmann. 1993. Deadline effects and inefficient delay in bargaining with endogenous commitment. J. Econ. Theory 60(2) 306-321.

[19] Fischbacher, U. 2007. z-Tree: Zurich Toolbox for Ready-made Economic Experiments. Exp. Econ. 10(2) 171-178.

[20] Gächter, S., A. Riedl. 2005. Moral property rights in bargaining with infeasible claims. Management Sci. 51(2) 249-263.

[21] Hennig-Schmidt, H. 1999. Bargaining in a Video Experiment. Determinants of Boundedly Rational Behavior. Springer, Berlin, Germany.

[22] Hoffman, E., M. L. Spitzer. 1985. Entitlements, rights,and fairness: An experimental examination of subjects' concepts of distributive justice. J. Legal Stud. 14(2) 259-279.

[23] Hoffman, E., K. McCabe, K. Schachat, V. Smith. 1994. Preferences, property rights, and anonymity in bargaining games. Game. Econ. Behav. 7(3) 346-380.

[24] Jan, T. 2009. Harvard classrooms, labs feel pinch of budget cuts, teaching ranks to get thinner. The Boston Globe. Online edition, (June 17).

[25] Kuon, B., G. R. Uhlich. 1993. The negotiation agreement area: An experimental analysis of two-person characteristic function games. Group Decis. Negot. 2(4) 323-345.

[26] Loewenstein, G., D. A. Moore. 2004. When ignorance is bliss: Information exchange and inefficiency in bargaining. J. Legal Stud. 33(1) 37-58.

[27] Lyons, T. 2009. Views on the news: Anger and sarcasm at findings of Guardian pay survey. Guardian, Online edition, (September 18).

[28] Messick, D. M., K. P. Sentis. 1979. Fairness and preference. J. Exp. Soc. Psychol. 15(4) 418434. 
[29] Moore, D. A., P. J. Healy. 2008. The trouble with overconfidence. Psychol. Rev. 115(2) 502517.

[30] Ortutay, B. 2008. Take-Two's Grand Theft Auto IV tops $\$ 500 \mathrm{M}$ in week 1 sales. Associated Press. Retrieved 2008-05-08.

[31] Ross, M., F. Sicoly. 1979. Egocentric Biases in Availability and Attribution. J. Pers. Soc. Psychol. 37(3) 322-336.

[32] Roth, A. E., J. K. Murnighan, F. Schoumaker. 1988. The deadline effect in bargaining: Some experimental evidence. Am. Econ. Rev. 78(4) 155-162.

[33] Rubinstein, A. 1985. A bargaining model with incomplete information about time preferences. Econometrica 53(5) 1151-1172.

[34] Schelling, T. 1956. An essay on bargaining. Am. Econ. Rev. 46(3) 281-306.

[35] Schiesel, S. 2008. A Video Game Star and His Less-Than-Stellar Pay. New York Times, Online edition (May 21).

[36] Schlicht, E. 1998. On Custom in the Economy. Clarendon Press. Oxford, U.K.

[37] Sebenius, J. K. 1992. Negotiation analysis: A characterization and review. Management Sci. 38(1) $18-38$.

[38] Staudohar, P. D. 1999. Labor relations in basketball: the lockout of 1998-1999. Mon. Labor Rev. April 3-9.

[39] Stuhlmacher, A. F., A. E. Walters. 1999. Gender differences in negotiation outcome: A metaanalysis. Pers. Psychol. 52(3) 653-677.

[40] Sutter, M., R. Bosman, M. G. Kocher, F. van Winden. 2009. Gender pairing and bargainingBeware the same sex! Exp. Econ. 12(3) 318-331.

[41] Thompson, L., G. Loewenstein. 1992. Egocentric interpretations of fairness and interpersonal conflict. Organ. Behav. Hum. Dec. 51(2) 176-197.

[42] Totilo, S. 2008. Grand Theft Auto IV posts record first-week sales. MTV News. Retrieved 2008-05-08.

[43] Walters, A. E., A. F. Stuhlmacher, L. L. Meyer. 1998. Gender and negotiator competitiveness: A meta-analysis. Organ. Behav. Hum. Dec. 76(1) 1-29. 
[44] Zuckerman, M. 1979. Attribution of success and failure revisited, or: The motivational bias is alive and well in attribution theory. J. Pers. 47(2) 245-287. 


\section{Appendix}

\section{A Additional Robust Tobit Regressions for Concessions}

Table A1: Explaining Relative Concessions and Concession Time in each Condition

\begin{tabular}{|c|c|c|c|c|}
\hline & \multicolumn{4}{|c|}{ Dependent Variable: Relative Concession } \\
\hline & noinfo & info & stoc & det \\
\hline \multirow{2}{*}{ Constant } & $1.05^{* * *}$ & $0.88^{* * *}$ & $0.98^{* * *}$ & $0.89^{* * *}$ \\
\hline & $(0.06)$ & $(0.07)$ & $(0.05)$ & $(0.06)$ \\
\hline \multirow{2}{*}{ Diff_Fair } & 0.05 & $-1.54^{* * *}$ & -0.57 & $-1.18^{* * *}$ \\
\hline & $(0.44)$ & $(0.47)$ & $(0.43)$ & $(0.42)$ \\
\hline \multirow{2}{*}{ Tie } & 0.21 & -0.01 & 0.08 & 0.20 \\
\hline & $(0.13)$ & $(0.15)$ & $(0.13)$ & $(0.18)$ \\
\hline $\log -L$ & -64.1 & -51.7 & -62.3 & -60.4 \\
\hline$F$ & 1.41 & $5.51^{* * *}$ & 1.24 & $4.04^{* *}$ \\
\hline$N$ & 90 & 84 & 91 & 83 \\
\hline
\end{tabular}

\begin{tabular}{ccccc}
\hline \hline & \multicolumn{3}{c}{ Dependent Variable: } & Concession Time \\
\cline { 2 - 5 } noinfo & info & stoc & det \\
\hline \multirow{2}{*}{ Constant } & $278.6^{* * *}$ & $408.4^{* * *}$ & $300.2^{* * *}$ & $367.9^{* * *}$ \\
& $(26.0)$ & $(32.8)$ & $(21.6)$ & $(29.3)$ \\
Diff_Fair & 151.3 & $443.8^{* *}$ & $318.7^{* *}$ & $616.7^{* * *}$ \\
& $(224.0)$ & $(254.1)$ & $(162.6)$ & $(219.6)$ \\
Tie & $-122.4^{* *}$ & $-152.2^{* * *}$ & $-155.0^{* * *}$ & -118.0 \\
& $(56.7)$ & $(58.5)$ & $(43.0)$ & $(58.5)$ \\
Log-L $L$ & -610.2 & -564.8 & -610.0 & -569.8 \\
$F$ & $2.37^{*}$ & $6.23^{* * *}$ & $10.79^{* * *}$ & $4.57^{* * *}$ \\
$N$ & 90 & 84 & 91 & 83 \\
\hline
\end{tabular}

Note: ${ }^{* * *}\left({ }^{* *}\right)$ indicates $1 \%(5 \%)$ significance level; robust standard errors in parentheses. Tie equals 1 if both department heads had the same performance, 0 otherwise. 


\section{B Experimental Instructions \& Debriefing Questionnaire}

As mentioned in the main body of the paper, there are some differences in the sequence of events across four conditions. The appendix below presents instructions for all conditions and these differences are mentioned with remarks. After this, the debriefing questionnaire used in the experiment is presented.

\section{General Explanations for Participants}

You are now participating in an economics experiment that is financed by several scientific institutions. In the experiment you can - next to the fixed show-up fee of 3 Euro - earn money with the decisions you make. Your earnings may also depend on the decisions of other participants and random events. How exactly is explained in this instructions document. It is, therefore, very important that you carefully read the following explanations. At the end of the experiment, you will be instantly and confidentially paid in cash all the money you have earned. During the experiment, we will speak of points instead of euro. Thus, all your income will be counted in points. The total number of points you have earned during the experiment will be exchanged into euro at the end of the experiment, where the exchange rate is

$$
100 \text { points }=65 \text { euro cents. }
$$

During the experiment you are not allowed to communicate. If you have questions then please raise your hand. One of us will come to you to answer your question.

On the following pages we will describe the exact procedure of the experiment.

\section{Information about the exact procedure of the experiment}

This experiment will consist of multiple parts. You will receive information about each part after the preceding part has ended. Be assured that your earnings in a particular part are unaffected by what happens in later parts.

This is the instructions of the first part of the experiment.

In this part of the experiment you are randomly paired with another participant. Neither during nor after the experiment will anybody be informed about who has been paired with whom. 
In the experiment, you and the person you are paired with ('other' for short) will act in the role of a head of department in a firm. Imagine that in this firm there is initially a total budget of 2050 points for your (you and the other) salaries. However, depending on the performances of both of you and some external factors (both of which will be explained below), the firm might have a larger (2710 points), the same (2050 points) or a smaller (1390 points) salary budget.

In any case, the top management of the firm does not want to dictate a salary distribution between the heads of department. Therefore, you are asked by the top management to bargain a salary distribution with the other head of department. If you can agree on a salary distribution within a pre-specified time, the firm pays your corresponding salaries (that is, you earn the points you agreed on). However, if you are not able to settle an agreement within the pre-specified time you are both 'fired', that is, you are not paid any salary (that is, you do not earn any points).

This part of the experiment consists of two stages. The first part consists of the determination of the salary budget and some questions. In the second part, bargaining over the salary budget takes place.

\section{Determination of performance and the salary budget:}

\section{Determination of performance.}

Your performance will be measured with a general knowledge quiz. Your performances potentially affect the salary budget you will later bargain on. The determination of performance is done as follows. Each participant has to answer questions. For each question there is exactly one correct answer and several wrong answers. The questions concern several fields of knowledge. In total there are 16 questions. Each participant receives the same questions in the same order. The head of department with the most correct answers has the better performance. You will answer the questions on the computer. You will have at most $\mathbf{3 0}$ seconds to answer each question. Unanswered questions count as wrong answers. A question will look like this: 
Which color is contained in the flags of all Islamic countries?
$\circ$ Red
$\circ$ Blue
- Green
○ Yellow
- Orange

OK

You answer a question by choosing the option you think is correct and subsequently striking the OK button within 30 seconds. The next question then shows up automatically. After you and the other head of department have answered all questions (or the time is over) you will see on the screen the salary budget you will have to bargain over with the other head of department. In the following, the determination of the salary budget is explained.

Remark 1 The following "Determination of salary budget" is used in the stoc condition.

\section{Determination of salary budget.}

First, it is randomly decided whether the salary budget is determined by external factors (e.g., demand conditions in the market for the firm's product) or the joint performance of you and the other head of department in the general knowledge quiz. More concretely, with $\mathbf{7 5 \%}$ chance, the salary budget is determined by external factors and $\mathbf{2 5 \%}$ chance it is determined by your joint performance, that is, the total number of correct answers in the general knowledge quiz. Below, it is explained in detail how external factors and performances affect the salary budget.

With a chance of $\mathbf{7 5 \%}$ the salary budget will be determined by external factors in the following way:

- With a chance of $\mathbf{1 / 3}$ (i.e. $\mathbf{3 3 . 3 \%}$ ), the salary budget will be $\mathbf{1 3 9 0}$ points

- With a chance of $\mathbf{1 / 3}$ (i.e. $\mathbf{3 3 . 3 \%}$ ), the salary budget will be $\mathbf{2 0 5 0}$ points 
- With a chance of $\mathbf{1 / 3}$ (i.e. $\mathbf{3 3 . 3 \%}$ ), the salary budget will be $\mathbf{2 7 1 0}$ points

With a chance of $\mathbf{2 5 \%}$ the salary budget will be determined by the joint performance of you and the other head of department in the following way:

- If the total number of correct answers by you and the other is from 0 to 10, then the salary budget will be $\mathbf{1 3 9 0}$ points.

- If the total number of correct answers by you and the other is from 11 to 20 , then the salary budget will be $\mathbf{2 0 5 0}$ points.

- If the total number of correct answers by you and the other is from 21 to 32 , then the salary budget will be $\mathbf{2 7 1 0}$ points.

\section{Summary of the determination of salary budget}

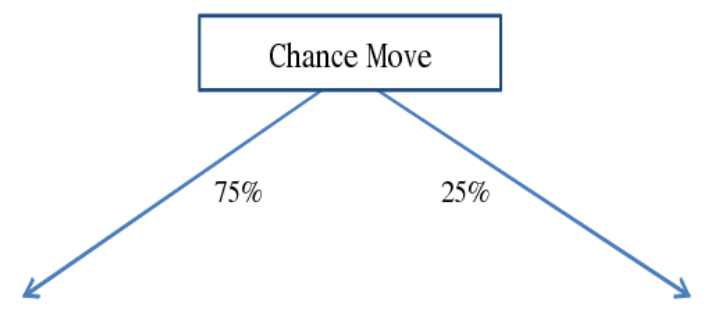

External Factors

Joint Performance

$\begin{array}{llll}\text { chance of } 1 / 3 \text { (i.e. 33.3\%) } & \mathbf{1 3 9 0} \text { points } & \text { Sum of correct answers from } \mathbf{0} \text { to } 10 & \mathbf{1 3 9 0} \text { points } \\ \text { chance of } 1 / 3 \text { (i.e. 33.3\%) } & \mathbf{2 0 5 0} \text { points } & \text { Sum of correct answers from } 11 \text { to } 20 & \mathbf{2 0 5 0} \text { points } \\ \text { chance of } 1 / 3 \text { (i.e. } 33.3 \% \text { ) } & \mathbf{2 7 1 0} \text { points } & \text { Sum of correct answers from } 21 \text { to } 32 & \mathbf{2 7 1 0} \text { points }\end{array}$


Remark 2 The following "Determination of salary budget" is used in the det condition.

\section{Determination of salary budget.}

The salary budget is completely determined by the joint performance of you and the other head of department in the general knowledge quiz. More concretely, it is determined by the total number of correct answers in the general knowledge quiz. Below, it is explained in detail how performances affect the salary budget.

The salary budget will be determined by the joint performance of you and the other head of department in the following way:

- If the total number of correct answers by you and the other is from 0 to 10, then the salary budget will be $\mathbf{1 3 9 0}$ points.

- If the total number of correct answers by you and the other is from 11 to 20 , then the salary budget will be $\mathbf{2 0 5 0}$ points.

- If the total number of correct answers by you and the other is from 21 to 32 , then the salary budget will be $\mathbf{2 7 1 0}$ points.

After you have finished the knowledge quiz you will learn the outcome of the described procedure and, hence, learn what the salary budget you have to bargain about is.

\section{Beliefs on the number of correct answers.}

Next you will be asked your beliefs about your and the other's performance in the general knowledge quiz. You can earn extra money depending on the accuracy of your estimation:

- If your estimation is exactly equal to the true number of correct answers, you earn $\mathbf{6 0}$ points.

- If your estimation is the true number of correct answers $-\mathbf{1}$ or $+\mathbf{1}$, you earn $\mathbf{3 0}$ points.

- If your estimation is the true number of correct answers $-\mathbf{2}$ or $+\mathbf{2}$, you earn 15 points.

- Otherwise, you earn 0 points.

You will be asked for an estimation of your own performance as well as for the performance of the other department head. Nobody except you will get to know these estimations. 
Remark 3 The following part is used only in the info condition.

Information about relative performance in the general knowledge quiz.

Next you will receive information on your screen about your actual performance in the general knowledge quiz in comparison to the other department head.

If you have more correct answers in the general knowledge quiz than the other department head, then you are the better performing department head and the other is the worse performing department head.

If you have less correct answers in the general knowledge quiz than the other department head, then you are the worse performing department head and the other is the better performing department head.

If you and the other have the same number of correct answers in the general knowledge quiz, then you and the other department head are equally performing.

This finishes the first stage of the experiment. The next stage is the bargaining over the salary budget. The instructions for this stage will be given shortly. Do you have any questions at this point? If you have a question please raise your hand. If there are no (more) questions we shall continue with the instructions. 


\section{The Bargaining}

You will have a maximum of 10 minutes to reach an agreement on the distribution of the salary budget, which is at your joint disposal. You do not have to use up all the bargaining time but must not exceed it. If you do not agree on a distribution within 10 minutes, then you will earn nothing from this bargaining stage! If you do agree on a distribution then you will earn your share.

The bargaining is done via the computer. During bargaining you will work with a screen that consists of four parts, which we will explain in what follows. (See screen-shot at the end of these instructions.)

1. In the upper-right part the salary budget you are bargaining over is shown. The clock right on the top shows how much bargaining time (in seconds) is still remaining.

2. In the lower-right part you see "Make and Send New Proposal" screen. There is a "SEND" button to confirm and send proposals.

3. In the upper-left part, the table shows all previous proposals, the identity of proposers (you or other), the number of the proposal, your and the other's proposed share of the salary budget, and the remainder share. For instance, if you have made the first proposal by proposing $\mathbf{x}$ to yourself and $\mathbf{y}$ to the other, then the first row of the table shows "You" as the proposer, "1" as the number of the proposal, "x" as the proposer's salary claim and, "y" as the remainder. Note, that the entries in the column "Proposer's Salary Claim" refer to the claim of the proposer and, hence, can be your claim or the claim of the other department head. The entries in the column "Remainder" therefore also refer to you or the other, depending on who made the proposal.

4. In the lower-left part, you see the other's and your currently valid proposals. There is also "Accept the Proposal" button to accept the other's currently valid proposal. If the other department head has not made any proposal to you yet, a "No proposals have been made to you yet" message is shown. Similarly, if you have not made any proposal, a "You have not made a proposal yet" message is shown.

If you want to make a first (or new) proposal you have to fill in two boxes in the lower-right quarter with corresponding shares for yourself and the other department head. The amounts you fill in should add up to the salary budget. Thereafter, you need to press the "SEND" button to send your proposal. The following rules apply: 
1. A proposal consists of an amount of points for you and an amount of points for the other department head. To switch a field forward you can either press the "TAB" key on your keyboard or you can click on the next field you want to fill in.

2. The sum of points cannot exceed the budget. Smaller sums are also not allowed. In case you make an invalid proposal in this sense, a "The numbers have to sum to the salary budget" message appears.

3. Only integer offers are allowed.

4. A sent offer is binding, that is, if the other department head accepts your proposal, bargaining is finished and both of you earn the points on which you have agreed upon. The same holds if you accept a proposal of the other department head. You can only accept the current proposal; earlier proposals are not valid any more.

Hence, as long as you have not pressed the "SEND" button you can still change the offer. A sent proposal is binding and shows up on the screen of the other department head as well as on your own screen. You can always make a new proposal, provided that neither you nor the other department head have accepted a proposal and provided that there is still some bargaining time left.

If you want to accept a currently valid proposal, you have to press the "Accept Proposal" button. If you have agreed upon a distribution you have to enter it in the corresponding space in your information \& documentation sheet.

This is the end of the instructions of this part of the experiment. Do you have any questions? If you have questions please raise your hand. If there are no (more) questions the experiment will start shortly. 


\section{Mood Question}

Cubicle \#: ..........

How do you feel at this moment? Please choose with the help of the figure the number that best describes how you feel.

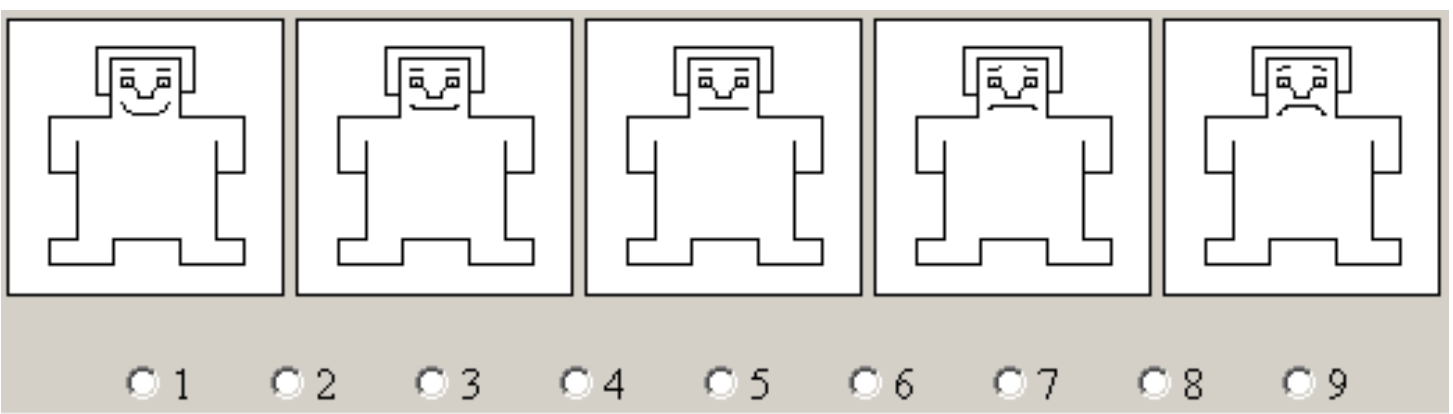


Remark 4 The results of the following bargaining stage is not relevant for the current paper. It is provided here only to keep the instructions in their original form.

\section{A New Experiment}

Now a new experiment takes place, which is very similar to the experiment you have just completed. In this experiment you have again to bargain with the other head of department, who is the same person as in the experiment you just finished.

Consider that one year has passed by and that the top management of the firm asks you again to bargain about the salary budget. There is one important difference with last years' procedure, however. Now there is no performance measurement. Suppose further that you and the other department head had an equal intermediate performance that was neither good nor bad for the firm.

Therefore, the salary budget that you will bargain about is determined purely by external factors (e.g., demand conditions in the market for the firm's product).

That is, the economic conditions and, hence, your salary budget are determined completely randomly. If the economic conditions turn out to be favorable, you bargain over $\mathbf{2 7 1 0}$ points of salary budget. If the economic conditions are unchanged you bargain over 2050 points of salary budget. If the economic conditions turn out to be bad you bargain over $\mathbf{1 3 9 0}$ points of salary budget. The salary budget is randomly determined in the following way:

- With a chance of $\mathbf{1 / 3}$ (i.e. $\mathbf{3 3 . 3 \%}$ ), the salary budget will be 1390 points

- With a chance of $\mathbf{1 / 3}$ (i.e. $\mathbf{3 3 . 3 \%}$ ), the salary budget will be 2050 points

- With a chance of $\mathbf{1 / 3}$ (i.e. $\mathbf{3 3 . 3 \%}$ ), the salary budget will be $\mathbf{2 7 1 0}$ points

As last year the top management does not want to dictate the new salaries. Therefore, it has decided to let you and the other department head bargain over the distribution of the new salary budget as you did in the past.

Otherwise the experiment proceeds precisely as the earlier one. You will bargain with the other department head about the distribution of the new salary budget. Again, these points will be exchanged to euros at the same rate (100 points $=65$ euro cents). In case of no agreement within 10 minutes, both of you receive nothing. As before, you will not be informed about the identity of 
the other department head. Otherwise the same rules as before apply. Please, enter the bargaining result in the new documentation sheet that comes along with these new instructions. After you have finished this part of the experiment you get paid your bargaining result from the earlier part of the experiment (including eventual earnings from your estimations of the numbers of correct answers in the general knowledge quiz) and the bargaining result from this part of the experiment The points you have earned in the earlier experiment will not be touched by this experiment, whatever the outcome is.

Do you have any further questions? If you have questions please raise your hand. If there are no (more) questions this part of the experiment will start shortly. 


\section{Randomization Procedure}

A random number generator independently draws two random numbers from a uniform distribution over $[0,1]$ interval, one for you and one for the other department head.

- If the sum of those two numbers is less than 0.8165 , the salary budget will be $\mathbf{1 3 9 0}$ points,

- If the sum of those two numbers is between 0.8165 and 1.1835, the salary budget will be $\mathbf{2 0 5 0}$ points,

- If the sum of those two numbers is more than 1.1835, the salary budget will be $\mathbf{2 7 1 0}$ points. 


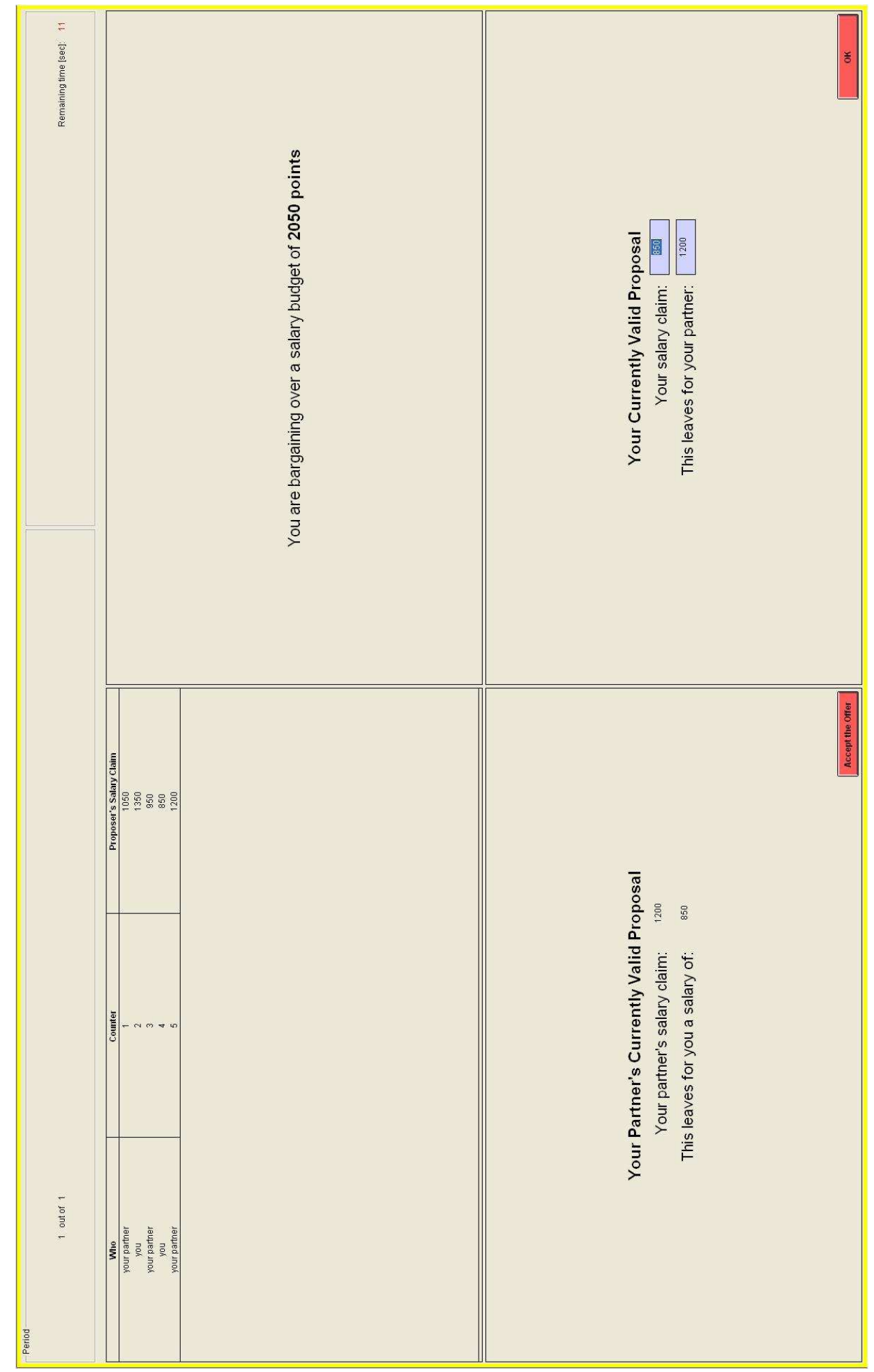




\section{Information and Documentation Sheet 1}

\section{Cubical \#:}

1- The size of the salary budget can be 1390 points, or 2050 points, or $\mathbf{2 7 1 0}$ points.

Remark 5 The following part is used in the det condition.

The actual salary budget is determined completely by the joint performance of myself and the other head of department.

The actually realized size of the salary budget is:

Remark 6 The following part is used in the stoc condition.

The actual salary budget is determined by the joint performance of myself and the other head of department with a chance of $25 \%$ and due to external factors with a chance of $75 \%$.

The actually realized size of the salary budget is:

2- My estimation about the number of correct answers in the general knowledge quiz is:

My own number of correct answers:

The other department head's number of correct answers:

Remark 7 The following part (part 3) is used in the info condition.

3- Actually I am the better/worse/equally performing department head (please strike through the inapplicable) and the other is the better/worse/equally performing department head (please strike through the inapplicable).

4- The bargaining outcome:

There was an agreement: ..... yes ..... no

In case of "yes":

The agreed share of the salary budget that goes to me:

The agreed share of the salary budget that goes to the other department head: 
Remark 8 The following part is not relevant for the current paper. It is provided here only to keep the instructions in their original form.

\section{Information and Documentation Sheet 2}

\section{Cubical \#:}

5- The second bargaining outcome:

The size of the salary budget can be $\mathbf{1 3 9 0}$ points, or $\mathbf{2 0 5 0}$ points, or $\mathbf{2 7 1 0}$ points.

The actual salary budget is determined completely by external factors.

The actually realized size of the salary budget:

There was an agreement: ..... yes ..... no

In case of "yes":

The agreed share of the salary budget that goes to me:

The agreed share of the salary budget that goes to the other department head: 


\section{Debriefing Questionnaire}

\section{Questionnaire -A-}

The following questions concern the determination of performance in the knowledge quiz. Please, indicate for all questions, by crossing the appropriate field, how strongly you agree with the statement. "1 = not at all", "7 = very".

1- In a knowledge quiz like this, pure luck decides who is able to answer more questions correctly.

1 2

3 4 5

6 7

2- The one with the better general knowledge is able to answer more questions correctly.
1 2 3 4 5 6 7

3- In my view the knowledge questions have been difficult.

$\begin{array}{lllllllll}1 & 2 & 3 & 4 & 5 & 6 & 7\end{array}$




\section{Questionnaire -B-}

We would now like to know how you assess your own general knowledge. Not all people have an equally good general knowledge. We ask you, therefore, to compare your own knowledge with that of the other participants in this experiment. By definition, of course, there is somebody who has the least general knowledge and somebody who has the best general knowledge. We ask you to indicate on the scale below where you position yourself with respect to your general knowledge, within the group of the participants of this experiment. Of course, since you do not know all participants of this experiment this is a difficult task. Nevertheless we ask you to make your selfassessment as accurate as possible. Please, position yourself by crossing the percentage interval on the scale below - where you think your own position relative to the other participants in this experiment is with respect to general knowledge. If you think, for example, that you are with your general knowledge at the top ten percent, then cross the percentage interval 91-100. If you think, for example, that you are with your general knowledge at the lowest ten percent, then cross the percentage interval 0-10.

Your estimation of your position within the group of the participants of this experiment with respect to your general knowledge:
○ $0-10$
$\circ 11-20$
○ $21-30$
$\circ 31-40$
○ $41-50$
$\circ 51-60$
○ $61-70$
○ $71-80$
- $81-90$
○ $91-100$ 


\section{Questionnaire -B- continued}

The following questions concern your behavior in the bargaining experiment.

1- Which factors influenced your bargaining behavior in the first bargaining stage?

Remark 9 Questions 2, 3, 4, 5, 6 and, 7 below are not relevant for the current paper. They are provided here only to keep the debriefing questionnaire in its original form.

2- Which factors influenced your bargaining behavior in the second bargaining stage?

3- Did you take the first bargaining stage outcome into account in the second bargaining stage?

4- If your answer to the previous question was YES, then please explain how the first bargaining stage outcome affected your behavior in the second bargaining stage. If your answer to the previous question was NO, then you can continue with the next question.

5- Did you use the first bargaining stage outcome as a reference point for negotiations in the second bargaining stage?

6- Which factors influenced your decision to use or not to use the first bargaining stage outcome as a reference point for the second bargaining stage?

7- Did your level of satisfaction play a role in your decision to use or not to use the the first bargaining stage outcome as a reference point in the second bargaining stage? 


\section{Questionnaire -C-}

To what extent do each of the following statements accurately describe you? Please indicate the degree to which you personally agree or disagree with each of the following statements by choosing a number from the scale below that reflects your opinion.

1- Never tell anyone the real reason you did something unless it is useful to do so.

$$
\begin{aligned}
& \text { ○ strongly disagree } \\
& \text { o disagree } \\
& \text { o neutral } \\
& \text { ○ agree } \\
& \text { o strongly agree }
\end{aligned}
$$

2- The best way to handle people is to tell them what they want to hear.

$$
\begin{aligned}
& \text { ○ strongly disagree } \\
& \text { ○ disagree } \\
& \text { - neutral } \\
& \text { ○ agree } \\
& \text { ○ strongly agree }
\end{aligned}
$$

3- One should take action only when sure it is morally right.

$$
\begin{aligned}
& \text { ○ strongly disagree } \\
& \text { ○ disagree } \\
& \text { ○ neutral } \\
& \text { o agree } \\
& \text { o strongly agree }
\end{aligned}
$$

4- Most people are basically good and kind.

$$
\begin{aligned}
& \text { o strongly disagree } \\
& \text { ○ disagree } \\
& \text { o neutral } \\
& \text { ○ agree } \\
& \text { o strongly agree }
\end{aligned}
$$

5- It is safest to assume that all people have a vicious streak and it will come out when they are given a chance.

$$
\begin{aligned}
& \text { ○ strongly disagree } \\
& \text { o disagree } \\
& \text { o neutral }
\end{aligned}
$$




$$
\begin{aligned}
& \circ \text { agree } \\
& \text { ○ strongly agree }
\end{aligned}
$$

6- Honesty is the best policy in all cases.

$$
\begin{aligned}
& \text { o strongly disagree } \\
& \text { o disagree } \\
& \text { o neutral } \\
& \text { o agree } \\
& \text { o strongly agree }
\end{aligned}
$$


7- There is no excuse for lying to someone else.

$$
\begin{aligned}
& \text { ○ strongly disagree } \\
& \text { o disagree } \\
& \text { o neutral } \\
& \text { ○ agree } \\
& \text { o strongly agree }
\end{aligned}
$$

8- Generally speaking, people won't work hard unless they're forced to do so.

$$
\begin{aligned}
& \text { ○ strongly disagree } \\
& \text { o disagree } \\
& \text { o neutral } \\
& \text { o agree } \\
& \text { o strongly agree }
\end{aligned}
$$

9- All in all, it is better to be humble and honest than to be important and dishonest.

$$
\begin{aligned}
& \text { ○ strongly disagree } \\
& \text { ○ disagree } \\
& \text { o neutral } \\
& \text { ○ agree } \\
& \text { o strongly agree }
\end{aligned}
$$

10- When you ask someone to do something for you, it is best to give the real reasons for wanting it rather than giving reasons which carry more weight.

$$
\begin{aligned}
& \text { ○ strongly disagree } \\
& \text { ○ disagree } \\
& \text { - neutral } \\
& \text { ○ agree } \\
& \text { o strongly agree }
\end{aligned}
$$

11- Most people who get ahead in the world lead clean, moral lives.

$$
\begin{aligned}
& \text { ○ strongly disagree } \\
& \text { o disagree } \\
& \text { o neutral } \\
& \text { ○ agree } \\
& \text { o strongly agree }
\end{aligned}
$$

12- Anyone who completely trusts anyone else is asking for trouble.

o strongly disagree

o disagree 


$$
\begin{aligned}
& \text { ○ neutral } \\
& \text { ○ agree } \\
& \text { o strongly agree }
\end{aligned}
$$

13- The biggest difference between most criminals and other people is that the criminals are stupid enough to get caught.

$$
\begin{aligned}
& \text { ○ strongly disagree } \\
& \text { ○ disagree } \\
& \text { ○ neutral } \\
& \text { ○ agree } \\
& \text { o strongly agree }
\end{aligned}
$$


14- Most people are brave.

$$
\begin{aligned}
& \text { ○ strongly disagree } \\
& \text { o disagree } \\
& \text { o neutral } \\
& \text { ○ agree } \\
& \text { o strongly agree }
\end{aligned}
$$

15- It is wise to flatter important people.

$$
\begin{aligned}
& \text { o strongly disagree } \\
& \text { ○ disagree } \\
& \text { o neutral } \\
& \text { ○ agree } \\
& \text { o strongly agree }
\end{aligned}
$$

16- It is possible to be good in all respects.

$$
\begin{aligned}
& \text { ○ strongly disagree } \\
& \text { ○ disagree } \\
& \text { o neutral } \\
& \text { ○ agree } \\
& \text { o strongly agree }
\end{aligned}
$$

17- P.T. Barnum was wrong when he said that there's a sucker born every minute.

$$
\begin{aligned}
& \text { o strongly disagree } \\
& \text { o disagree } \\
& \text { o neutral } \\
& \text { o agree } \\
& \text { o strongly agree }
\end{aligned}
$$

18- It is hard to get ahead without cutting corners here and there.

$$
\begin{aligned}
& \text { ○ strongly disagree } \\
& \text { o disagree } \\
& \text { o neutral } \\
& \text { ○ agree } \\
& \text { o strongly agree }
\end{aligned}
$$

19- People suffering from incurable diseases should have the choice of being put painlessly to death.

$$
\begin{aligned}
& \text { ○ strongly disagree } \\
& \text { o disagree } \\
& \text { o neutral }
\end{aligned}
$$




$$
\begin{aligned}
& \text { ○ agree } \\
& \text { o strongly agree }
\end{aligned}
$$

20- Most people forget more easily the death of their parents than the loss of their property.

o strongly disagree

o disagree

o neutral

$\circ$ agree

o strongly agree 


\section{Questionnaire -D-}

Please click the option you find most appropriate! " $0=$ not at all willing to take risks", " $10=$ very willing to take risks"

How do you personally assess yourself: Generally speaking, are you a person who is ready to take risks or are you trying to avoid risks?

$$
\begin{array}{lllllllllll}
0 & 1 & 2 & 3 & 4 & 5 & 6 & 7 & 8 & 9 & 10
\end{array}
$$

One can behave differently in different circumstances. In the following circumstances, how would you assess your readiness to take risks?

Driving a car?

$\begin{array}{lllllllllll}0 & 1 & 2 & 3 & 4 & 5 & 6 & 7 & 8 & 9 & 10\end{array}$

Making a financial investment?

$$
\begin{array}{lllllllllll}
0 & 1 & 2 & 3 & 4 & 5 & 6 & 7 & 8 & 9 & 10
\end{array}
$$

In leisure time and when doing sports?

$$
\begin{array}{lllllllllll}
0 & 1 & 2 & 3 & 4 & 5 & 6 & 7 & 8 & 9 & 10
\end{array}
$$

Regarding your professional career?

$\begin{array}{lllllllllll}0 & 1 & 2 & 3 & 4 & 5 & 6 & 7 & 8 & 9 & 10\end{array}$

Regarding your health?

$\begin{array}{lllllllllll}0 & 1 & 2 & 3 & 4 & 5 & 6 & 7 & 8 & 9 & 10\end{array}$

Regarding confidence in strangers?

$$
\begin{array}{lllllllllll}
0 & 1 & 2 & 3 & 4 & 5 & 6 & 7 & 8 & 9 & 10
\end{array}
$$

Please, consider what you would do if you face the following situation: Imagine that you win 100,000 Euro in a lottery. Right after receiving the prize, you receive a new offer from a reputable lottery company, which includes the following: there is a chance to double the amount of money you bet. In case you win, the prize will be immediately paid out. However, there is also an equally high risk of losing half of the money you bet. You can invest the 100,000 Euro into the lottery in whole or in part in the following ways or reject the offer entirely.

What part of the lottery winnings would you put in this new lottery, which is, on the one hand, risky and promises gains, on the other hand?

○ The whole amount of 100.000 Euro 
○ An amount of 80.000 Euro

○ An amount of 60.000 Euro

- An amount of 40.000 Euro

○ An amount of 20.000 Euro

○ Nothing at all 


\section{Questionnaire -D- continued}

Another question about risk-taking. Please consider what you would do if you face the following situation: Imagine that you win 100,000 Euro in a lottery. Right after receiving the prize, you receive an investment offer from a reputable bank, which includes the following: within two years, there is a chance to double the amount of money you invest. However, there is also an equally high risk of losing half of the money you invest. You can invest the 100,000 Euro in whole or in part in the following ways or reject the offer entirely.

What part of the lottery winnings would you put in this investment opportunity, which is, on the one hand, risky and promises gains on the other hand?

○ The whole amount of 100.000 Euro

$\circ$ An amount of 80.000 Euro

- An amount of 60.000 Euro

- An amount of 40.000 Euro

○ An amount of 20.000 Euro

○ Nothing at all 


\section{Questionnaire -E-}

At the end some statistical questions:

Age:

Gender:

Study:

How much money per month do you have at your disposal (net of accommodation costs)?: 